\title{
How to reliably detect molecular clusters and nucleation mode particles with Neutral cluster and Air Ion Spectrometer (NAIS)
}

\author{
Hanna E. Manninen ${ }^{1}$, Sander Mirme ${ }^{2,3}$, Aadu Mirme ${ }^{2,3}$, Tuukka Petäjä ${ }^{1}$, and Markku Kulmala ${ }^{1}$ \\ ${ }^{1}$ Department of Physical Sciences, P.O. Box 64, 00014 University of Helsinki, Finland \\ ${ }^{2}$ Institute of Physics, Laboratory of Environmental Physics, University of Tartu, Ülikooli 18, 50090 Tartu, Estonia \\ ${ }^{3}$ Airel, Ltd., Observatooriumi 5, 61602 Tõravere, Estonia \\ Correspondence to: Hanna E. Manninen (hanna.manninen@helsinki.fi)
}

Received: 26 January 2016 - Published in Atmos. Meas. Tech. Discuss.: 6 April 2016

Revised: 13 June 2016 - Accepted: 24 June 2016 - Published: 3 August 2016

\begin{abstract}
To understand the very first steps of atmospheric particle formation and growth processes, information on the size where the atmospheric nucleation and cluster activation occurs, is crucially needed. The current understanding of the concentrations and dynamics of charged and neutral clusters and particles is based on theoretical predictions and experimental observations. This paper gives a standard operation procedure (SOP) for Neutral cluster and Air Ion Spectrometer (NAIS) measurements and data processing. With the NAIS data, we have improved the scientific understanding by (1) direct detection of freshly formed atmospheric clusters and particles, (2) linking experimental observations and theoretical framework to understand the formation and growth mechanisms of aerosol particles, and (3) parameterizing formation and growth mechanisms for atmospheric models. The SOP provides tools to harmonize the world-wide measurements of small clusters and nucleation mode particles and to verify consistent results measured by the NAIS users. The work is based on discussions and interactions between the NAIS users and the NAIS manufacturer.
\end{abstract}

\section{Introduction}

Understanding of the detailed formation mechanisms and the chemical composition of vapours, which participate in the atmospheric particle formation processes, has clearly benefited from direct atmospheric measurements and improvements in measurement techniques (Manninen et al., 2010; Kulmala et al., 2013, 2014; Ehn et al., 2014). Aerosol particles have global effects on Earth's climate and regional effects on air quality. In atmospheric particle formation, we study the phase transition from gas phase precursors to aerosol particles. Atmospheric new particle formation can start via molecular clustering, and it is followed by cluster activation for enhanced growth (Kulmala et al., 2013). The freshly formed particles grow by multicomponent condensation. When aerosol particles grow further to sizes where they can act as cloud condensation nuclei, they start to have effect on the climate. One of the main objective of atmospheric aerosol science is to contribute to the reduction of scientific uncertainties concerning global climate change issues, particularly those related to aerosol-cloud interactions (IPCC, 2013).

Although the Neutral cluster and Air Ion Spectrometer (NAIS, Mirme and Mirme, 2013) is a relatively recently developed instrument, it has already been used widely in many atmospheric particle formation studies. First field observations by Kulmala et al. (2007) showed the capacity of the instrument for direct detection of the newly formed particles, and later the long-term observations in field lead into fundamental understanding of the cluster formation and activation (Manninen et al., 2009). The NAIS has been used in various environments in all continents to study both natural and anthropogenic aerosols, both during short-term campaigns and during long-term field studies. For example, the NAIS has been deployed in the boundary layer (e.g. Manninen et al., 2010), in the middle troposphere (Laakso et al., 2007; Boulon et al., 2011; Rose et al., 2015), in the upper free troposphere (Mirme et al., 2010), and in the tropics (Suni et al., 2008; Martin et al., 2010; Siingh et al., 2013), at the middle and high latitudes (Lihavainen et al., 2007; Manninen et al., 
2010) and in the polar regions (Virkkula et al., 2007), and in the remote, rural, and urban areas (Tiitta et al., 2007; Backman et al., 2012; Hirsikko et al., 2007, 2013; Herrmann et al., 2014; Jayaratne et al., 2014). Several laboratory studies have been conducted to investigate connection between the small cluster ions and new particle formation (e.g. Ortega et al., 2012; Franchin et al., 2015; Duplissy et al., 2016; Kirkby et al., 2016).

\subsection{Special considerations when measuring cluster and nucleation mode particles with the NAIS}

The instrument measures the number size distribution of atmospheric ions and particles by collecting signal simultaneously with many electrometers. The complete distribution of both polarities is determined rapidly using parallel columns. This is the main advantage of the NAIS, but it also creates convoluted instrument construction, and complex maintenance and calibration procedures.

The sampling and detection of small ions and freshly formed particles is demanding. Firstly, the charging probability of neutral nanometer-sized particles is very low and the concentration of growing freshly formed particles is often less than 10 particles per $\mathrm{cm}^{-3}$. Thus, efficient charging and large sample-flow rates are essential for increasing the amount of collected particles. Secondly, the clusters and small particles can undergo rapid transformations and their composition can change during sampling before the actual detection. Thus, the residence time of the air within the instrument should be short and the temperature, humidity and trace gas composition of the sheath air should be similar to ambient. Thirdly, reducing diffusional and electrical inlet losses of charged clusters and nanoparticles is a crucial requirement for the measurement set-up. Thus, the inlet lines should be as short as possible, and the inlet must be grounded, and there should be no un-grounded conductive or dielectric material near the inlet. Finally, the calibration and verification of the NAIS under laboratory conditions is essential to confirm that the field results are reproducible and comparable to avoid misinterpretation of data and incorrectly calculated nucleation parameters.

In this paper we present a method to measure number size distribution of clusters at sub- $3 \mathrm{~nm}$ and nanoparticles at sub$25 \mathrm{~nm}$ (i.e. nucleation mode particles; see Kulmala et al., 2012). This standard operation procedure (SOP) is based on scientific and technical discussions between the NAIS and the Air Ion Spectrometer (AIS) users among the ACTRIS (Aerosols, Clouds, and Trace gases Research InfraStructure network) partners as well as with the (N)AIS manufacturer Airel Ltd., Estonia. The procedure work is led by the University of Helsinki. The aim is to provide consistent results and unified datasets measured with the NAIS around the world, as the NAIS results improve our understanding of the processes producing atmospheric nanoparticles. These results can be used for developing aerosol process parameterization for the atmospheric models, and validating and constraining the global models. Note that the procedures presented here apply to instrumentation which are currently in use. As the NAIS instrument is under continuous development, the maintenance, calibration and data processing methods need to be updated and modified accordingly.

\subsection{Procedure overview}

The SOP (Sect. 3) is written for the NAIS users with different background. The procedure has three main parts that explain the required actions:

Section 3.1-3.2 detail how to calibrate and verify the instrument both in laboratory and in the field. This is essential during long-term operation, and prior and after shortterm campaigns to confirm that the results are reliable.

Section 3.3-3.5 detail how to install, operate and maintain the instrument during the field, laboratory or chamber measurements. Various environmental conditions are considered.

Section 3.6-3.7 detail how to process the collected data including the data corrections and data quality checks. This step is typically required before the new particle formation data analysis, which is described in detail in Kulmala et al. (2012).

Critical topics are highlighted. Section 4 provides a troubleshooting section for the most typical issues during the NAIS operation. In Sect. 5, some typical ion and particle number size distributions measured with the NAIS are presented.

\section{Instrumentation}

\subsection{Neutral cluster and Air Ion Spectrometer}

The NAIS is a multichannel aerosol mobility spectrometer capable of measuring a mobility distribution of charged particles and ions of both polarities in an electrical mobility range from 3.2 to $0.0013 \mathrm{~cm}^{2} \mathrm{~V}^{-1} \mathrm{~s}^{-1}$, and a size distribution of total particles in a size range from 2.0 to $42 \mathrm{~nm}$. A controlled charging of the aerosol sample with a needle-corona charger followed by an electrical filtering of the corona-generated ions, is used to measure the total aerosol particles. Manninen (2011) and Mirme and Mirme (2013) describe the principles of NAIS design and raw signal processing in more details.

\subsection{Instrument schematics and flow chart}

Figure 1 illustrates that the NAIS can have a "1-blower", "3blower" or "4-blower flow system". Whereas in the 1-blower system all flows are controlled by one blower, in the 3-blower system there is one sample flow blower for the instrument. In 
(a)

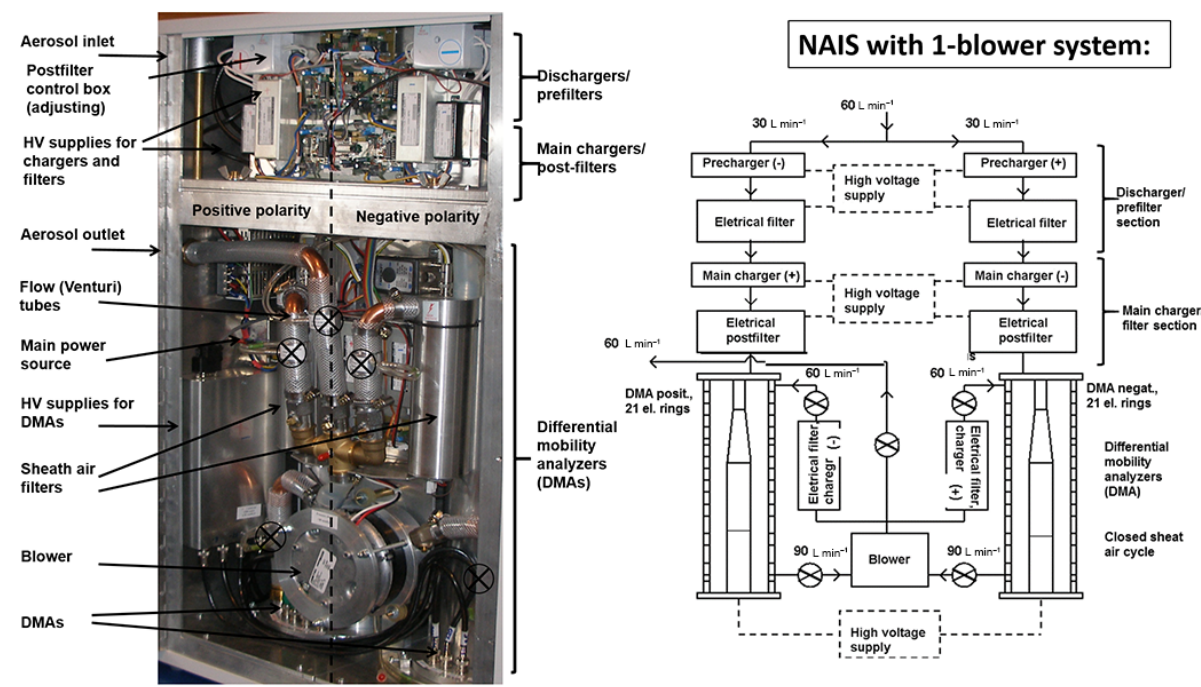

(b)

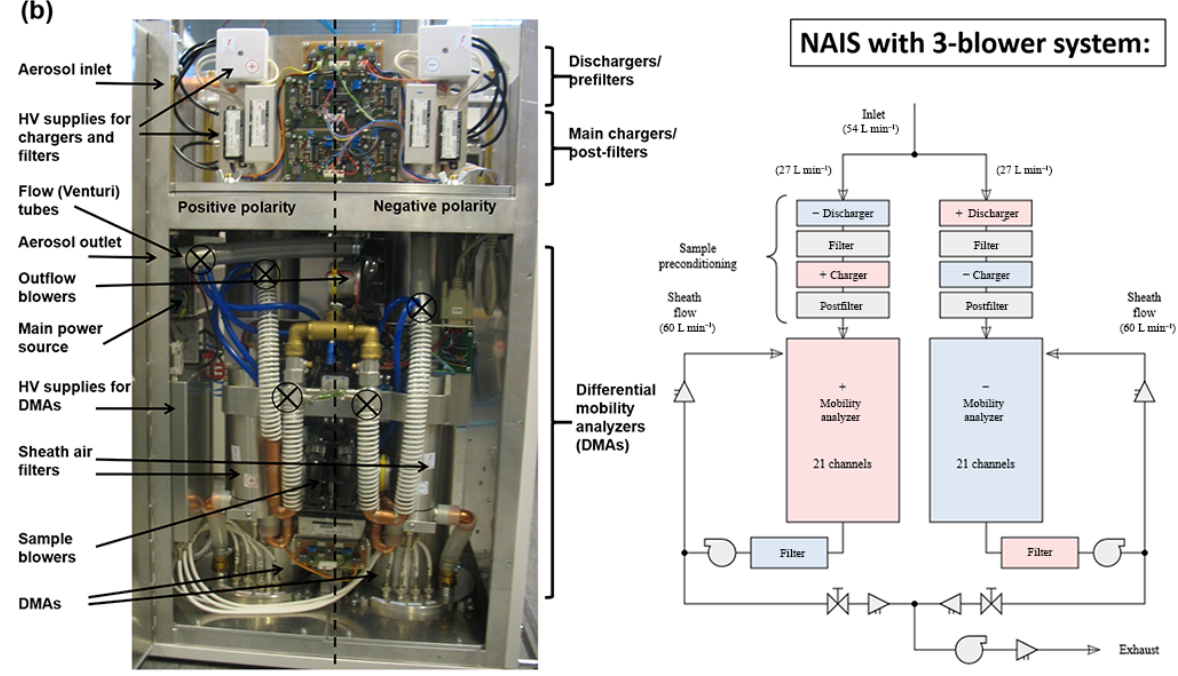

Figure 1.

the 4-blower version both columns have a separate sample flow blower. All the flow rates - sheath flow for both polarities and sample flow (either single or separate) - are measured using Venturi tubes and differential pressure sensors. The blowers are automatically controlled to maintain the correct flow rates. The flow sensors are calibrated at Airel Ltd., Estonia.

\subsection{Measurement modes}

The mobility analyzers of the NAIS are preceded by a software controlled sample preconditioning unit. Depending on the measurement mode of the instrument, the unit may filter particles out to measure a zero signal, charge the particles to measure neutral aerosol, or leave the sample untouched to measure naturally charged ions.
The four main measurement modes of the instrument are as follows: (1) Ions mode is used to measure naturally charged particles and ions. All parts of the preconditioning unit are switched off and the aerosol sample is not modified. (2) Particles mode is used to measure all particles including the uncharged fraction. The main charger and "post-filter" are switched on. (3) Alternating charging mode is similar to the particle mode but additionally the discharger is switched on. This has the effect of "neutralizing" the sample and so it improves the instrument performance in the case of a nonsteady-state charge distribution. (4) Offset mode is used to measure the zero signal and noise levels of the electrometers. The particles are first charged by the discharger with ions of a opposite polarity to that, which is measured by the analyser and then filtered out. This way no detectable particles will enter the analyser. 


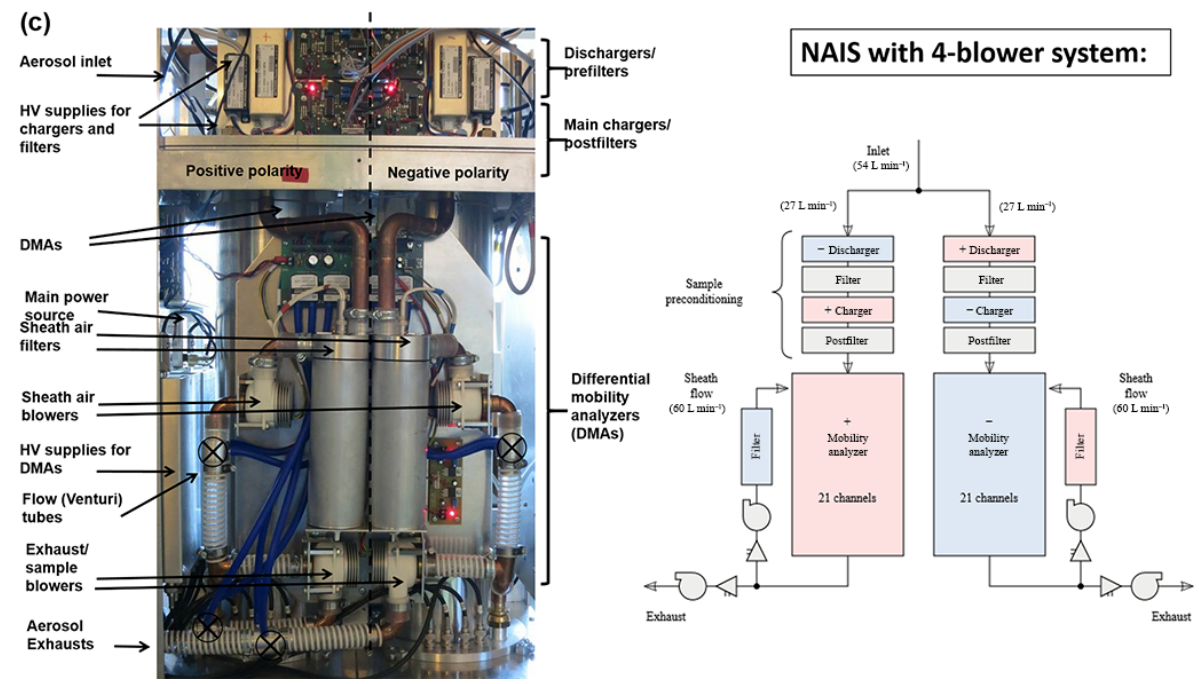

Figure 1. A schematic of the NAIS with: (a) 1-blower, (b) 3-blower, and (c) 4-blower flow system.

Table 1. Recommended measurement modes and measurement cycle of the NAIS.

\begin{tabular}{lll|ll}
\hline & \multicolumn{2}{c|}{$\begin{array}{c}\text { Ion } \\
\text { measurements }\end{array}$} & \multicolumn{2}{c}{$\begin{array}{c}\text { Particle } \\
\text { measurements }\end{array}$} \\
\cline { 2 - 5 } & $\begin{array}{l}\text { Pos. } \\
\text { ions }\end{array}$ & $\begin{array}{l}\text { Neg. } \\
\text { ions }\end{array}$ & $\begin{array}{l}\text { Pos. } \\
\text { charging }\end{array}$ & $\begin{array}{l}\text { Neg. } \\
\text { charging }\end{array}$ \\
\hline DMA polarity & positive & negative & positive & negative \\
\hline Discharger & off & off & off & off \\
Filter & off & off & off & $\begin{array}{l}\text { off } \\
\text { on, }\end{array}$ \\
Charger & off & off & on, \\
pos. HV & neg. HV \\
Post-filter & off & off & on & on \\
\hline Duration (s) & \multicolumn{2}{c|}{$90(45)$} & \multicolumn{2}{c}{$90(45)$} \\
\hline
\end{tabular}

\begin{tabular}{lll}
\hline & \multicolumn{2}{c}{ Offset measurements } \\
\cline { 2 - 3 } & Pos. polarity & Neg. polarity \\
\hline DMA polarity & positive & negative \\
\hline Discharger & on, neg. HV & on, pos. HV \\
Filter & on & on \\
Charger & off & off \\
Post-filter & off & off \\
\hline Duration (s) & & $30(30)$ \\
\hline
\end{tabular}

\subsection{Recommended measurement cycle}

The recommended measurement cycle for the NAIS groundbased measurements is alternating between offset, ions, and particle modes as follows: offset -30 ; ions -90 ; particles 90; where the numbers represent measurement times in different modes in seconds. Reliable offset measurements are vital for the accuracy of the instrument itself and for the final number size distribution. The offset signal is estimated using a linear regression on the electric current measurements from the previous and following offset measurement cycles. The variance of the electric current signal during the offset cycle is used to estimate the noise level of individual electrometers. It is recommended that the duration of the offset measurement is between 30 and $60 \mathrm{~s}$, and the total length of the measurement cycle is between 2 and 5 min (Table 1).

\subsection{Sample preconditioning unit with corona chargers and electrical filters}

This is presented in Fig. 2. Although bipolar radioactive chargers are the most widely used chargers due to their welldefined charge distribution (Wiedensohler, 1988; Reischl et al., 1997), unipolar diffusion chargers can attain much higher charging efficiency levels (Intra and Tippayawong, 2009). Thus, the NAIS uses the unipolar corona discharge ionization. The high voltage (HV) supplies feed the corona charger needles (typically with $2-3 \mathrm{kV}$ ). The voltages are controlled by a feedback system to maintain a constant electric current of the corona ions to the outer electrode of the charger volume.

Both measurement columns use two corona chargers. The first charger is called the discharger and it can charge particles in the opposite polarity to the one, which is measured by the subsequent mobility analyser. The discharger currents are $-20 \mathrm{nA}$ for the positive column and $20 \mathrm{nA}$ for the negative one during the offset operating mode. In the alternating charging mode the currents are -10 and $10 \mathrm{nA}$, respectively. The discharger is followed by an electric filter, which is used during the offset operating mode to remove the charger ions and charged particles. Although these particles would not be directly detected by the analyser due to their wrong polarity, the space charge would still induce unwanted electric cur- 

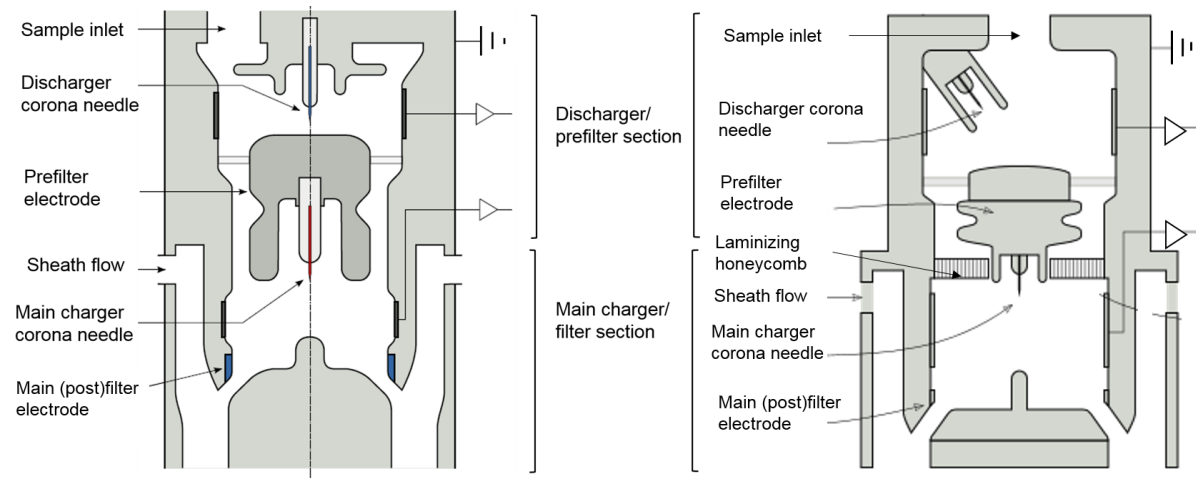

Figure 2. A cross section of the aerosol preconditioning unit and upper part of the mobility analyzer for old generation (left column) and new generation (right column) of the NAIS. Grounding of the different parts are visualized.

rents to the measurement electrodes. The set point voltage of the filter is $500 \mathrm{~V}$, when switched on.

The main charger current is set to $25 \mathrm{nA}$ for the positive charger and to $-22 \mathrm{nA}$ for the negative one. The difference in charging currents compensates for the difference in the charging efficiency of the chargers (due to the different mean mobility of positive and negative ions, Manninen et al., 2011).

\subsection{Notice when using the particles mode}

The corona charger ions have a mobility diameter range of $1.0-1.6 \mathrm{~nm}\left(1.3-0.8 \mathrm{~cm}^{2} \mathrm{~V}^{-1} \mathrm{~s}^{-1}\right.$, Manninen et al., 2011). These sizes define the absolute lower detection limit of the NAIS in the particle mode. The size range of corona chargergenerated ions measured by the NAIS is illustrated in Fig. 3 with a gray shaded area. The figure shows that the charger ions were clearly smaller than $2 \mathrm{~nm}$. The post-filter is used to cut-off the corona ions generated by the charger, and consequently the small charged particles are filtered out together with ions used for the charging. The post-filter voltage is typically $30-150 \mathrm{~V}$. If the corona ions were allowed to pass into the analyzer they would saturate the first measurement channels and cause invalid signals in the later channels. As can be seen from Fig. 4, the electrical filtering of the charger ions and the inability to remove all the naturally charged particles plays an important role in determining the lowest detection limit to approximately $2 \mathrm{~nm}$ in electrical mobility equivalent size. For more details see Sect. 3.7.4.

\section{Procedure}

We encourage all NAIS users to follow this procedure, which is based on earlier scientific work by Mirme et al. (2007, 2010), Asmi et al. (2009), Manninen et al. (2009, 2011), Kulmala et al. (2012), Mirme and Mirme (2013), and Wagner et al. (2016). The procedure has been motivated by a need of reliable long-term field measurements and by the compara-

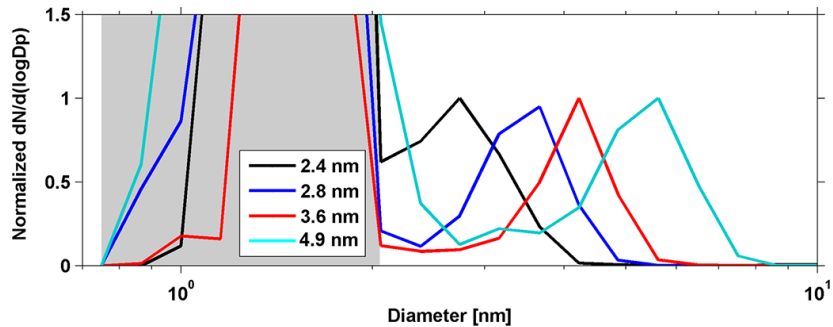

Figure 3. The size distributions of four different sizes of neutral silver particles measured with the NAIS (positive charging, automatic post-filtering). The shaded area represents the size range of corona charger ions.

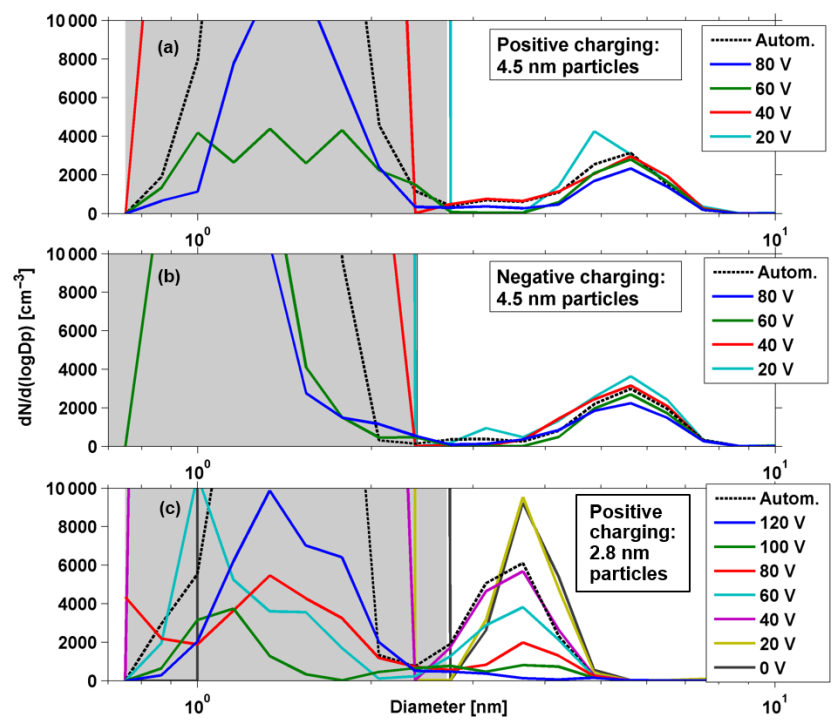

Figure 4. The size distribution of $4.5 \mathrm{~nm}$ neutral silver particles measured with the NAIS using (a) positive and (b) negative corona charging, and (c) the size distribution of $2.8 \mathrm{~nm}$ particles measured with positive charging. Different lines represent different post-filter voltages. 
bility of such long-term field data. We aim to improve the comparability of the results by improving the instrument's verification, maintenance, and data processing procedures.

\subsection{Instrument calibration}

Prior to the measurements, the NAIS flow sensors and the electrometer background levels should be checked. The NAIS software monitors the flows using Venturi flow metres during the measurements continuously. The NAIS flows should be compared to a reference flow metre. If a discrepancy is detected, the flow sensors need to be recalibrated to update the calibration coefficients in the measurement software. The electrometer background can be checked by passing particle-free air into the instrument or by performing a concentration calibration as a function of particle size. The voltages in the inner electrode of the differential mobility analyser (DMA) should be measured before and after ambient measurements. The background and DMA voltages are continuously recorded by software during the measurements.

It is recommended that ion spectrometer users take part in the calibration and intercomparison workshops organized in co-operation by University of Helsinki and Airel Ltd. The ion spectrometers should be calibrated often enough, preferably at the calibration workshops. The goal is to organize these workshops on a regular basis. During the workshops the ion spectrometer flows are calibrated and their mobility classification and concentration measurements are verified.

\subsubsection{CRITICAL: determining the flows of the NAIS}

The sheath and input flows of the NAIS are critical for a precise determination of the particle mobility and concentration. Thus, prior to the mobility and concentration calibrations the instrument should be cleaned, leak tested and flow checked. The cleaning procedures are essential before the determination of flows. If dirt enters the tubing or nets inside the instrument, the flow resistance will alter the volume flow through the Venturi tubes (see Sect. 3.5.2). When maintenance cleaning is done regularly, the instruments can perform well for extended periods and flows stay stable (Gagné et al., 2011). This is primarily relevant for the instruments with the 1-blower flow system as the correct flow balance is very delicate (see Option A). The newer instruments with three and four blowers will maintain flow stability for much longer periods without the maintenance and will only require recalibration in case a simple check indicates a problem (see Option B).

\section{Leak tests}

Leak tests can be done using several methods. Alternative 1: the volume flow rate measured from the inlet and outlet should match when no leaks exist. This is sufficient in case the instrument is operated at atmospheric pressure and a low pressure drop inlet is used. Alternative 2: this alternative is

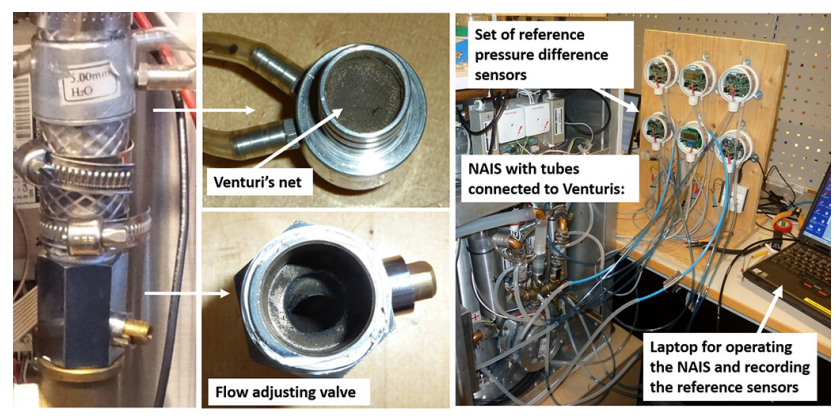

Figure 5. On the left: a dirty Venturi tube and its net, and a dirty flow adjustment valve in a close-up from the NAIS operated in Marikana, South Africa. Both were required to be cleaned well before the flow verification. On the right: an example of a set-up for flow checks with external pressure difference sensors, which are connected to the 5 Venturi tubes to record all the values simultaneously, including the pressure difference over the blower.

carried out by blocking the inlet and outlet, applying overpressure or under pressure inside the instrument, and measuring the flow rate required to maintain the constant pressure. The recommended range is $50-100$ mbar overpressure or under pressure. Overpressure above 200 mbar may damage the instrument. Alternative 3: when the inlet is closed, the recorded sample flow rate should drop to a value well below $10 \mathrm{~L} \mathrm{~min}^{-1}$. This method is suitable for a quick check; however it is not completely reliable.

The flow calibration should be done once a year during the long-term operation, or before and after a short-term campaign measurement. However, the flows should be determined always, when a blower is replaced or a large leak is detected and sealed.

\section{Option A: flow verification with pressure sensors for the 1-blower system}

For the 1-blower system, in Fig. 1a, one blower runs all the flows. Five flow rates (sheath and output flows of both analysers and the total exhaust flow) are measured with Venturi tubes. In normal operation only the exhaust flow rate is measured continuously, as it is the most sensitive to the changes of all the other flows. Each Venturi tube has an individual calibration where an exact pressure drop, corresponding to the specified flow rate, is determined in normal conditions. The Venturi calibration values are provided by Airel Ltd, when the instrument is manufactured. The Venturi calibration is not needed to be done by the user, but the pressure drop should be verified and the flow adjusted, if needed. This procedure is illustrated in Fig. 5. The differential pressure over the five Venturi tubes should be measured with a reference differential pressure measurement device (e.g. TESTO 512 0-2 hPa), and checked against the value obtained from the calibration to be sure that the flow rate though the Venturi is correct. If the checked pressure difference does not correspond to the 


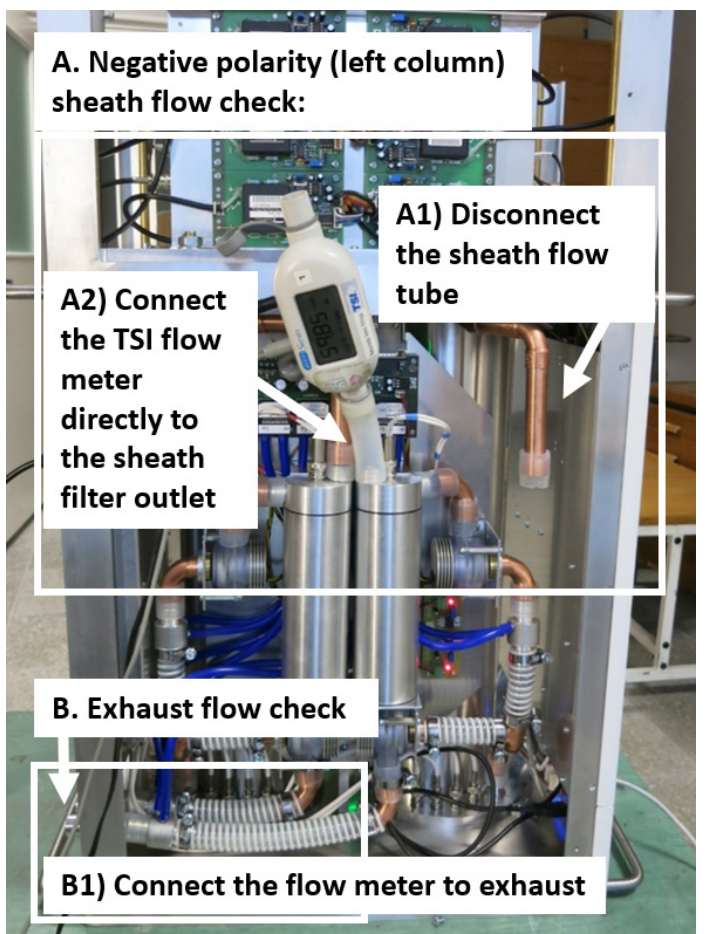

Figure 6. A quick and easy sheath flow check for 4-blower system using a TSI flowmeter which is placed directly after the sheath air filter.

calibrated ones, the flows should be adjusted to match the calibrated pressure difference while keeping a constant overpressure $\left(80 \mathrm{~mm} \mathrm{H}_{2} \mathrm{O}\right)$ after the blower (measured with, e.g. TESTO 512 0-20 hPa).

The procedure for determining the flows for the 1-blower system is as follows: first, the user verifies that the sample and outlet flows are equal and no leaks exist. Second, the blower power should be adjusted so that the overpressure after the blower is $80 \mathrm{~mm} \mathrm{H}_{2} \mathrm{O}$. Third, each of the five flows are measured via the pressure difference from the Venturi tubes, and adjusted, if required, to match the values given in the Venturi calibration (while keeping a constant overpressure after the blower). To adjust the Venturi's pressure drop turn the brass knob which is located on a side of the flow adjusting valve with pliers (middle bottom panel, Fig. 5). To fix misbalanced flows, either the valve on the higher pressure drop side should be slightly closed or the other valve slightly opened. Last, the user should check that the sampling flow remains at $\sim 60 \mathrm{~L} \mathrm{~min}^{-1}$. For a full pressure sensor calibration the user should contact Airel Ltd. to provide detailed information on the flow calibration set-up and possibly update the measurement software.
Option B: flow verification with flowmeters for 3- and 4-blower systems

For the 3- and 4-blower system, in Fig. 1b-c, the verification involves measuring the volumetric flow rates with an external flowmeter (e.g. TSI 4000 series) at the instrument's exhausts and after the sheath air filters. First, place a reference flowmeter at both exhausts (measure one exhaust flow tube at time) to verify the sample flow at the Venturi tubes, which are located just before the exhaust tubes. The sample flow and exhaust flow should be identical when the instrument is not leaking. Second, disconnect a sheath flow tube and place the flowmeter after the sheath air filter to verify the sheath flow at Venturi tubes, which are located prior to the blower and filter. Figure 6 shows a quick and easy way to check the sheath flow of the negative polarity for the 4-blower system. Repeat this step for the sheath flows for the both polarities. For a simple instrument check it is sufficient to compare the reference flowmeter value to the corresponding NAIS flowmeter value. Note that the NAIS flowmeters show the actual volume flow rate that is not adjusted to standard temperature and pressure conditions. A full flow sensor calibration can be done by the user but it requires assistance from Airel Ltd. to provide a customized calibration software, followed by processing the results and updating the measurement software.

In case of the 3- and 4-blower systems, the instrument includes a barometric pressure sensor that is actively used to determine the correct flow rate. The instrument sensor value should be compared to a reference barometric pressure sensor and the calibration coefficients should be adjusted, if necessary. To change these calibration coefficients, contact to Airel Ltd.

In the case of the 3-blower system, there is only one sample flow Venturi sensor in the instrument that measures the total flow from both analysers. An additional step is required to confirm the sample flow balance of the negative and positive analysers. This involves adjusting the two valves before the Y-connector, where the sample flows join from both of the analysers. The two Venturi tubes next to the valves should be measured simultaneously using two handheld differential pressure sensors. The calibrated values for these pressure differences are either written inside the instrument or available from Airel Ltd. The valves should be adjusted accordingly.

\subsubsection{CRITICAL: determining the voltages of the NAIS}

The response of the DMA high voltage (HV) supply should be followed from the instrument diagnostics. Correct sizing of small ions and particles in the DMA is highly sensitive to the accuracy of the applied HV. Particular care is required particularly in the low voltage range, which is used to classify the smallest ions. The voltages in the inner electrode are $\pm 9, \pm 25, \pm 220$, and $\pm 800 \mathrm{~V}$, depending on the polarity of the DMA. For the newer versions of the NAIS manufactured 
after 2014 (serial numbers NAIS27 and NAIS-4-1, and later) the corresponding voltages are $\pm 9, \pm 35, \pm 150, \pm 700 \mathrm{~V}$. To confirm the voltages with an independent measurement, a HV-probe with ultra-low impedance should be used.

\subsubsection{Determining the losses and sizing accuracy of the NAIS}

In the size range of the cluster ions and small neutral particles the calibration is a challenging task due to limitations in the capability of reference instruments, generation of proper calibration aerosols, and instrumentation for the size-separation. Possible calibration set-ups are presented in detail in Asmi et al. (2009), Gagné et al. (2011), Kangasluoma et al. (2013) and Wagner et al. (2016). To determine the losses and the sizing accuracy of the full size range of the NAIS requires an extensive suite of instrumentation: (1) in the sub- $10 \mathrm{~nm}$ size range with a high resolution H-DMA (Herrmann-DMA; Herrmann et al., 2000; Kangasluoma et al., 2016) to determine the transfer functions and losses, (2) monomobile molecular standards (Ude and Fernández de la Mora, 2005) to determine specific mobility calibration, and (3) a Hauke DMA (Winklmayr et al., 1991) to perform the mobility and concentration calibrations in the size range from 4 to $40 \mathrm{~nm}$. Prior to the loss and mobility calibration, the flows need to be verified as described above.

Wagner et al. (2016) studied the accuracy of the NAIS in a supplementary laboratory calibration. They concluded that in ion mode the sizing of the NAIS was very accurate, regardless of the version of the data inversion, and the ion number concentrations were underestimated $15-30 \%$, depending on the version of the data inversion. Using a correction introduced by Wagner et al. (2016), the uncertainty of the ion concentration measurement of the NAIS can be reduced to $\sim 10 \%$, allowing the NAIS to be used in quantitative ion cluster and charged particle studies.

\subsection{Instrument verification}

Prior to the field or laboratory measurements, the electrometer background levels, and the balance of number concentration measured with the positive and negative columns should be checked. Between calibrations the NAIS should be regularly compared to a reference instrument for a period of few days per year, especially during the long-term operation. The verification should always be done when the measurement location changes.

\subsubsection{Intercomparison with other instrumentation}

It is recommended that different methods are used in parallel to determine the cluster and nucleation mode number concentration in order to avoid misinterpretation of results (Kulmala et al., 2012). Participation in the intercomparison workshop is recommended. Another opinion is to perform a sideby-side intercomparison at the measurement site, if a suitable supporting instrumentation is available (e.g. ion spectrometer, Gerdien counter, condensation particle counter, differential/scanning mobility particle sizer, or air conductivity measurement, e.g. Asmi et al., 2009; Gagné et al., 2011).

\subsubsection{CRITICAL: balance between negative and positive measurement columns}

To verify instrument operation prior a measurement campaign, the balance of number concentration measured with the positive and negative columns should be checked. The concentration verification can be done by generating population of sample aerosol (in equilibrium charge distribution) and measuring it with both columns. A good agreement (10$20 \%$ ) between the polarities gives confidence that the instrument is working properly. In the following sections we describe three options for the verification experiments before instrument deployment.

\section{Option A: orange peeling experiment}

Peeling a citrus fruit and thus releasing D-limonene, a common monoterpene, into the room air can lead to aerosol particle formation in the indoor environment (Vartiainen et al., 2006). This is a fast, easy and cheap way to generate nucleation mode aerosol particles over a whole size range of the NAIS as the D-limonene oxidation products trigger the particle formation and subsequent growth (Gagné et al., 2011). Finding the right amount of fruits to peel to generate the correct amount of vapour can take a few trials. Note that there should be sufficient ozone concentration and low background aerosol concentration in the room to facilitate new particle formation and growth.

\section{Option B: indoor and outdoor sampling experiment}

Fast concentration verification between the polarities can be done by sampling from indoor and outdoor. The indoor sample due to efficient air-conditioning is typically dominated by cluster ions and can be used to check the balance between small ions, whereas outdoor sample has a typically abundant Aitken mode and can be used to test larger ions and particles (Hirsikko et al., 2007).

\section{Option C: a test with small ions from an external charger}

Extensive number concentrations in the range from $\sim 10^{2}-$ $10^{6} \mathrm{~cm}^{-3}$ in both positive and negative cluster ions can be generated by using an external radioactive source (Steiner et al., 2014). A radioactive source producing bipolar charger ions should be placed right in front of the NAIS inlet. By varying the flow rate through the external charger, the user can vary the number concentration of the charger-generated ions. This data verifies the balance between the positive and negative cluster ions and their proper size classification. Please note that typically the negative cluster ions have 

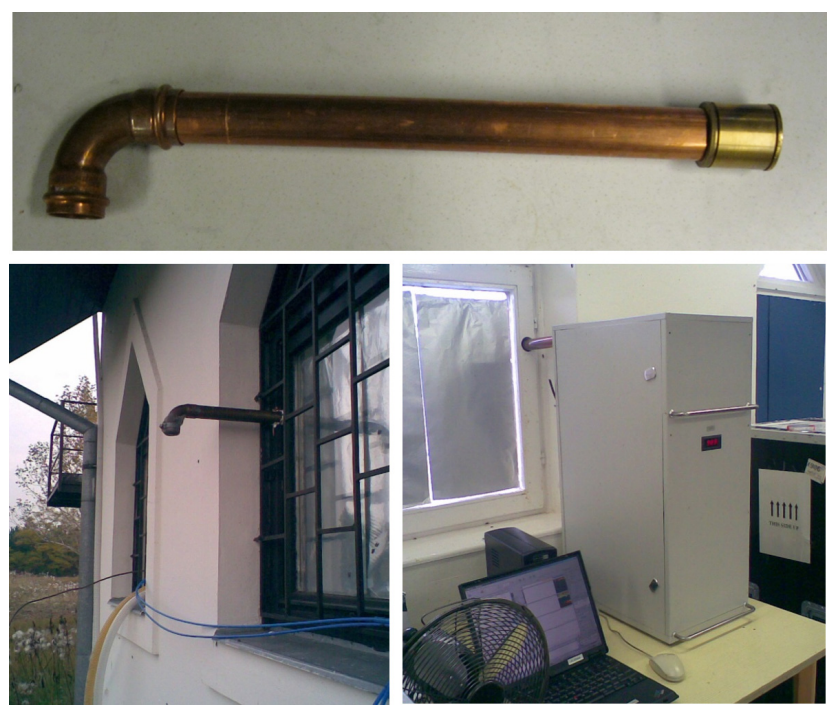

Figure 7. Example an aerosol sampling inlet for the NAIS used at K-puszta field station, Hungary. A grid is missing in the top image from the end of the sampling line. Below an instrument set-up on field.

higher mobility than the positive cluster ions. The charger ion size distribution also varies as a function of carrier gas composition (Manninen et al., 2011).

\subsection{Instrument installation}

\subsubsection{CRITICAL: inlet design and installation}

A recommended inlet is a $50 \mathrm{~cm}$-long metallic tube (diameter $35 \mathrm{~mm})$ with a bend $\left(90^{\circ}\right.$ angle facing down) and metallic net (grid size $1 \mathrm{~mm}$ ) in the end of the inlet line; see Fig. 7. The brass inlet connector with a metallic net inside (sold by Airel Ltd.) is recommended to be used. Although the instrument and the inlet line can be placed vertically or horizontally, the horizontal orientation for the inlet line is recommended. In the vertical inlet set-up the precipitation may easily enter the instrument and damage the instrument and lead to poor data quality. Sampling height depends on the surroundings. It can vary from 2 to $15 \mathrm{~m}$ above ground level (a.g.l.; height of the surrounding canopy/buildings). Note that the Earth's electrode effect can cause an imbalance between polarities (negative and positive ion number concentrations), when the inlet height is below $4 \mathrm{~m}$ a.g.l. The ionosphere has positive charge and Earth's surface has a negative charge. Thus, Earth's surface works as a negative electrode which attracts the positive ions and repels the negative ions close at ground level (Hoppel, 1967).

The inlet lines should include a proper rain cover as the rain droplets can interfere the measured spectra (Tammet et al., 2009). In the field conditions, the user should make sure that rain does not get into the instrument enabled by high sampling flow rate. If there is a chance of water dripping into the inlet, the end of the inlet tube should point at least slightly downwards. A metallic grid in the inlet is recommended. The performance of the mobility analyser is sensitive to insects and other material which may settle on the electrodes or electrometers. These impurities can cause corona discharge, noise and parasitic currents. Furthermore, the pressure drop from the inlet to the instruments should be kept in the range of few $\mathrm{hPa}$. This is facilitated by a regular cleaning of the inlet grid.

\section{Option A: inlet with a minimized diffusional and electrical losses}

Due to diffusional losses of small particles the inlet lines needs to be kept as short as possible and as straight as possible, while keeping the flows close to laminar. Enhanced diffusional particle losses may occur in the sampling lines with bends or elbows. The particle losses increase with a decreasing radius of the bend. It is very essential that the inlet lines and connectors should be made from a conductive material (preferably stainless steel) to avoid losses caused by a static electric charge. Experience has shown that non-conductive tubing (e.g. plastics) may remove a considerable fraction of any charged particles by the unwanted electrostatic forces. A rough estimation for particle losses should be done on the measurement site after the installation by measuring with and without inlet set-up by performing a short measurement exercise with and without the inlet construction.

\section{Option B: an inlet with aerosol sample conditioning}

When working in a warm and humid atmospheric environment, dew point temperature of the sample flow can reached in the measurement cabin or container $\left(20-25^{\circ} \mathrm{C}\right)$. This requires that the aerosol sample flow has to be dried, either directly in the sampling line or at the instrument. During earlier deployments in South America (Backman et al., 2012) drying by heating has been used for the NAIS. The inlet line and at the instrument is heated above ambient temperature to avoid water condensing inside the tubing or the instrument. At high altitude sites and other sites with heavy snow storms heated inlet has been used to avoid ice blocking the inlet line. Heating of the sample flow may change the sample by evaporating the most volatile particulate species. To limit relative humidity in the aerosol sample flow, we do not recommend a membrane dryer (e.g. Nafion ${ }^{\text {TM }}$ dryer), or a silicabased aerosol diffusion dryer due to high aerosol sample flow rates and increased diffusional losses of clusters and small particles. When sampling in a highly polluted environment, we recommend adding a core sampling inlet and a dilution of the sample with aerosol-free bypass flow (drying by dilution; see Wagner et al., 2016). 


\subsubsection{Sampling location and measurement set-up}

In a typical field operation, the NAIS should be placed indoors in an air-conditioned space. The instrument should be operated in a temperature of $5-35^{\circ} \mathrm{C}$ to avoid a malfunction of the electric circuits (chargers and filters, HV supplies). The instrument inlet and the immediate vicinity should be grounded well so that the sampled ions are not attracted by the static charge on nearby surfaces. The instrument itself should be grounded via the power cable. The measurement cycles should be set based on scientific aims, briefly summarized in the sections below.

\section{Option A: ground site measurement}

In close to sea level, the NAIS software uses a fixed sheathflow rate value of $60 \mathrm{~L} \mathrm{~min}^{-1}$ and a sample-flow rate value of $30 \mathrm{~L} \mathrm{~min}^{-1}$ (1-blower system) and $27 \mathrm{~L} \mathrm{~min}^{-1}$ (3- and 4blower system) per DMA, when calculating the ion and particle number size distributions. The deviation of the flow rate from the default value should be taken into account during subsequent data processing by applying a correction to the number size distributions. The volumetric flow rates are typically recorded by the instrument. However the measured distributions are not automatically corrected in the case if the flow rates deviate from the nominal values. When the sample-flow rate is recorded, the ion and particle number concentrations can simply be multiplied by (default flow rate) / (recorded or measured flow rate) ratio. When the sheath flow has changed from default values the ion and particle size distributions should be re-inverted (assistance from Airel Ltd. is needed). For the ground-based measurements, the recommended measurement cycle is as follows: offset 30; ions - 90; particles - 90 .

\section{Option B: high-altitude site measurement}

At high-altitude sites, the NAIS (with 3- and 4-blower systems) volumetric sample flow rate is kept constant whereas the sheath-flow rate is varied automatically (Mirme et al., 2010). The automatic adjustment of the sheath-flow compensates changes in the particle mobility in exceptionally low or varying air pressures and temperatures. Thus, the classified particle size range is kept invariant of the pressure and temperature changes. The effect of ambient temperature variations to measured ion and charged particle mobilities is considered small because of warming in the sampling line. The 1-blower system is not recommended for high-altitude or aircraft measurements and we recommend upgrading it into the 3- and 4-blower system. Otherwise, the user needs to keep the blower operating in the right volumetric flow range manually or apply a correction to the number size distributions, and a separate airflow calibration is needed for the 1-blower system in the variable environmental conditions.

\section{Option C: flight measurement}

Several improvements were made to the airborne NAIS to able to measure the size distribution and concentration of ions as a function of altitude inside a pressurized aircraft (see Mirme et al., 2010). When measuring inside a pressurized aircraft, the instrument leaks have to be particularly well controlled. We recommend using the upgraded 3- and 4-blower system in the aircraft deployments. These versions of the NAISs automatically adjust the aerosol sample- and sheathflow rates so that the particle sizing and volume sample-flow rate remain constant regardless of ambient pressure. Typical modifications to the NAIS in the airborne measurements are (1) replacing the electricity supply to match the system used in the aircraft, (2) designing a special inlet system to sample air from outside the aircraft, (3) reinforcing the instrument rack and attaching it into the aircraft frame, (4) modifying the instrument for increased air tightness in the case it is used in a pressurized cabin, and (5) setting the length of the measurement cycle to a minimum. If the inlet is in over pressure, the exhaust flow may need to be restricted with valves (e.g. adding some soft tubing and a pinch cock). For the airborne measurements the recommended measurement cycle is as follows: offset -30 ; ions -45 ; particles -45 .

\section{Option D: laboratory and chamber measurement}

In chamber measurements, where it is required to minimize the amount of sample air, the high sample flow rate of the NAIS is a challenge. In such an application, the it is recommended to operate the NAIS with a recirculation system, which dilutes the inlet sample flow with filtered air coming from the exhaust of the instrument. In other words, the sample air from the chamber is diluted with a portion of the exhaust air of the instrument, which is filtered with a highefficiency particulate air (HEPA, e.g. Camfil Megalam, MD 14-305X305X66-10) filter and mixed with the sample air (in more details; see Franchin et al., 2015). The pressure drop on the filter and dilution mixer should be below $10 \mathrm{hPa}$ to ensure that the sample flow blowers of the NAIS are able to comfortably circulate the air. The use of the dilution system allows reduction of the fresh sample flow from 54 to $20-30 \mathrm{~L} \mathrm{~min}^{-1}$.

Otherwise in the laboratory measurements, where the available sample flow rate is limited and sampled concentrations are small, it is recommended to use only one polarity (column) of the NAIS (e.g. Manninen, 2011) at a time depending on the polarity of the user needs. This is possible only with the 4-blower system, where the columns work completely independently. To disable one column, disconnect and close the corresponding tube at the inlet Y-connector which divides the flows to the two analysers or alternatively close the corresponding exhaust outlet. The instrument configuration files should be modified to switch off the blowers for the disabled column. This must be done to avoid damage to the blowers. When the NAIS is used in aerosol ex- 
posure studies with extremely high concentrations $\left(\sim 10^{5}-\right.$ $10^{6} \mathrm{~cm}^{-3}$ ), we recommend adding a core sampling inlet with appropriate dilution as well.

\subsection{Monitoring and adjusting instrument parameters in varying environmental conditions}

A large number of measurement parameters are automatically monitored by the instrument. They include for example flow rates, blower control signals, charger currents and filter voltages. Most of the parameters are continuously checked by the Spectops measurement software and diagnostic warning flags indicate if a problem is detected. The presence of a warning does not definitely mean that the measurements are invalid. The user should always understand and confirm the reason why the warning is raised and fix the issue when necessary. Similarly, an absence of the warning signal does not guarantee that the measurements are correct.

The corona currents and filter voltages are adjusted by varying the HV supply feed voltage. The discharger and the main charger are automatically controlled with a feedback loop driven by the current measured from the surrounding electrode. The post-filter is controlled according to the current measured by the first electrometer channels in particles measurement mode. The blowers are actively controlled according the measured flow signals from the Venturi tubes.

The automatic adjustment with the feedback works as long as all the feedback controls are between 0.1 and $4.9 \mathrm{~V}$ which the NAIS user should check. A sensor value starts to deviate from a target value if the control voltage goes too close to 0.0 or $5.0 \mathrm{~V}$. In more detail, in the Spectops diagnostic a sensor value is the value measured by the analog-digital converter. It is converted to the actual parameter value by a predefined equation (e.g. "airflow sensor" to "airflow"). The parameters which are automatically controlled by the digital feedback have a control and a target value. The target value is the ideal sensor value, the goal (e.g. for the sample airflow speed the target value equals the sensor voltage that matches $54 \mathrm{~L} \mathrm{~min}^{-1}$ ). The control value is the output voltage of the digital-analog converter that adjusts some function in the instrument (e.g. airflow blowers). The algorithms will automatically adjust the control value so that the sensor value matches target value (e.g. if airflow sensor is below the airflow target the airflow control is consequently increased).

\subsubsection{Monitoring the instrument performance}

The instrument operation should be checked daily by the user. Figure 8 summarizes a recommended checklist for instrument's performance monitoring. Airel Ltd. provides tools for this. There are two programs in the measurement software package provided with the NAIS: (1) Spectops for running the measurements and viewing online data and (2) Retrospect for viewing and reprocessing the recorded data offline. The Airel Ltd. has an extensive diagnostic checklist in the NAIS manual: http://wiki.airel.ee/Docs/NaisManual. They are not repeated here, but we recommend the user to follow the checklist.

\subsubsection{Flow measurement control settings}

The blowers are automatically adjusted using a software digital feedback loop controller based on the flow sensors and barometric sensor so that the mobility analysis and sampling volumetric flow rate remain constant. When measuring through an inlet with a high pressure drop or in polluted conditions, the blower might be under heavy strain as this requires the blower to be operated with a higher voltage. A similar situation is reached, when the flow resistance increases over time due to settled atmospheric aerosols (instrument getting dirty). This calls upon a frequent cleaning of the instrument in the polluted conditions.

\subsubsection{CRITICAL: controlling corona discharging}

To keep the corona charger efficiency at a constant level independent of environmental conditions, the corona needle voltage is adjusted by varying the HV supply feed voltage according to an active feedback loop. The efficiency of the corona charger is directly determined by the charger ion concentration, which is proportional to the electric current carried by the corona ions to the surrounding electrode inside the charger volume. Thus, the discharger and the main charger are controlled with a feedback loop driven by the current measured from the surrounding electrode. In normal operating conditions of the NAIS, the corona-needle voltage is in the range of $2-3 \mathrm{kV}$. Over time the electrode (i.e. corona needle/wire) gets worn out because of aerosol particles settling on the needle. This will typically cause the corona voltage fluctuate as the corona ignition voltage increases and a stable discharge can no longer be maintained. For this reason, the NAIS corona needles need to be cleaned regularly.

\subsubsection{CRITICAL: adjusting the post-filter (i.e. electrical filter in particle mode)}

In the particle mode the post-filters remove the cluster ions generated by the corona chargers. The post-filter settings should be optimized according to environmental conditions. Typically the filter operates with a voltage of $40-100 \mathrm{~V}$. The corona-generated ions are at the same size range as the smallest particles measured by the NAIS. The set point of the post-filtering voltage is a compromise between the removal of corona-generated ions and the penetration of small aerosol particles. The main electrical filter voltages are adjusted by varying the HV supply feed voltage according to an active feedback loop. In the 3- and 4-blower systems, the user can change the target values by modifying the configurations with Spectops software (Mirme and Mirme, 2013). In the 1-blower systems, the post-filter voltage is adjusted by the user manually; see Supplement S2 for details. Figure 9 shows 


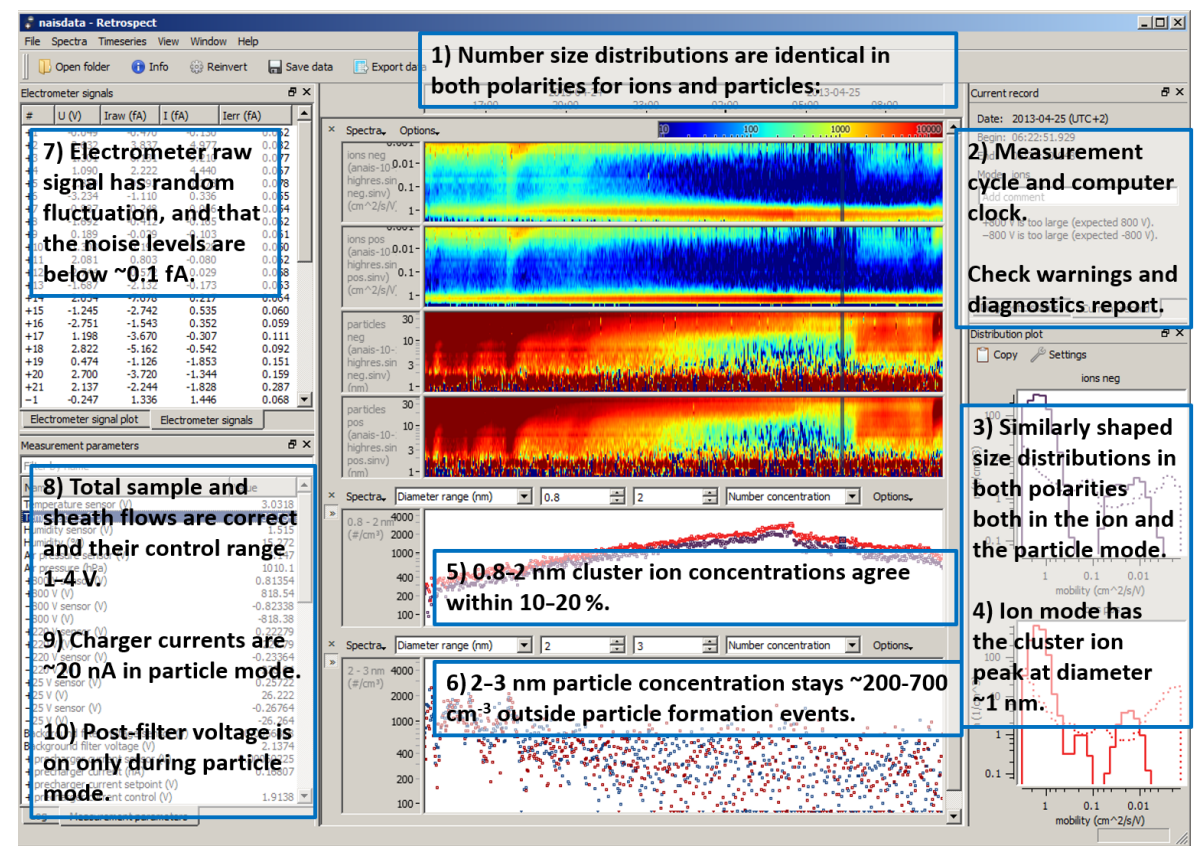

Figure 8. The NAIS measurement software (Spectops.exe or Retrospect.exe) is recommended to be used for checking that the instrument is operating properly by following the steps listed in the figure.

when to change settings or adjust manually the post-filter during the particle measurements. We recommend that in the continuous field measurements the automatic adjustment is used, if possible. In the laboratory experiments with rapidly changing or unusual aerosol distributions, the automatic adjustment should be switched off (Manninen et al., 2011).

\subsection{CRITICAL: maintenance requirements}

As important as the instrument verification, a regular maintenance of the NAIS to maintain the calibration during the operation is critical. The maintenance procedures include instrument cleaning, leak tests, and checks on the condition of corona-needles, proper insulation between the inner and outer electrodes, and proper instrument grounding and inlet operation.

\subsubsection{Inlet cleaning}

The inlet net and inlet tubing should be cleaned thoroughly in 1-3 week intervals to maintain the optimal aerosol sample flow and reduce the amount of dirt settling on the analyzer. The required interval depends on the local aerosol concentrations.

\subsubsection{Routine instrument cleaning}

During long-term operation the NAIS should be cleaned every 1-3 months due to the deposition of particulate matter inside the instruments. Within the cleaning procedures all parts, which are in contact with the sample- and sheath-flow, should be thoroughly wiped using delicate task disposable wipes (e.g. Kimberly-Clark Kimtech Science Kimwipes) and alcohol (e.g. 2-propanol). The wipes which get easily worn out and leave fibers should be avoided. The metallic nets inside the Venturi flow tubes (i.e. tubes with narrow slits for adjusting the volumetric flow) should be cleaned carefully. When dirt settles onto the nets, the flow resistance increases, and consequently the volume flow through the Venturi tubes decreases. This alters the mobility classification. An ultrasonic bath is recommended for cleaning these nets. Instead of nets, the instruments with 3 or 4-blowers have typically honeycomb-shaped pieces to make the flow laminar. These are less likely to become dirty and a careful cleaning with a brush or pressurized air is sufficient. Overall, the 3and 4-blower instruments are significantly less susceptible to flow deviation issues. The corona-needle chargers should be cleaned (scraped with a sharp knife) regularly (1-3 month intervals) to make sure that the corona-generated ion concentration is maintained at a constant level.

\section{Notice while cleaning the NAIS}

Use plenty of isopropanol and Kimwipes. Do not scratch the inner surfaces of the NAIS. Clean all the surfaces which are in contact with the sample and sheath air flows. Do not wipe the plastic parts with isopropanol, clean them with de-ionized water to avoid leaving a conductive film on the surface. Always wear gloves when handling the DMAs and sample preconditioning units. After the cleaning procedures, check that 
(a)

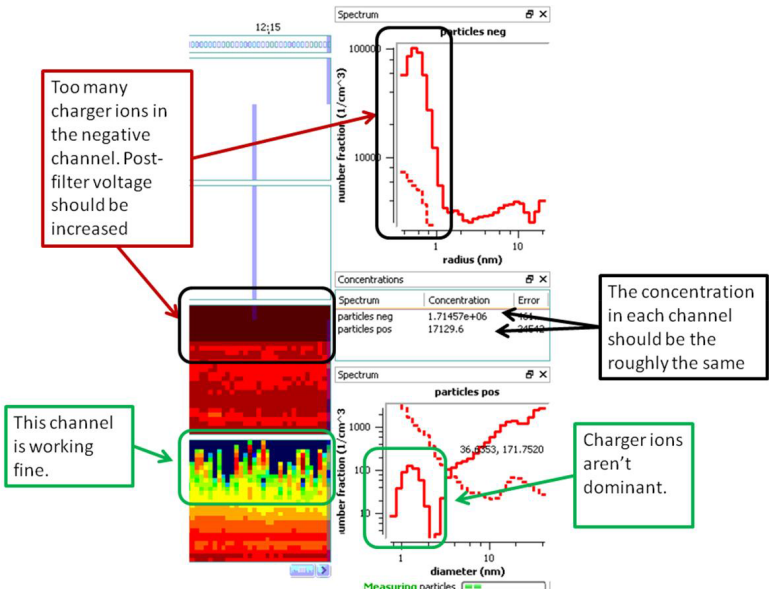

(b)

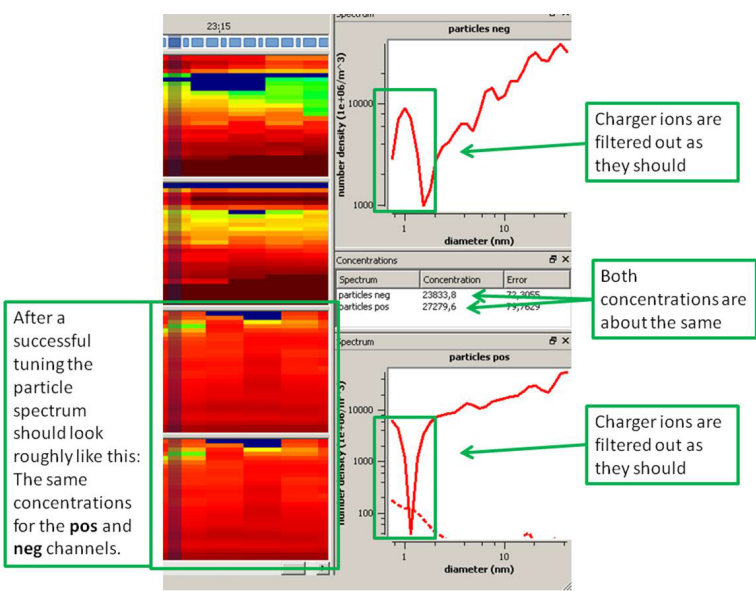

Figure 9. Adjusting post-filter during the particle measurement mode: (a) what to look for, when tuning the post-filter voltage for a bad column (here negative polarity), and (b) how the particle number size distribution should look like after the tuning.
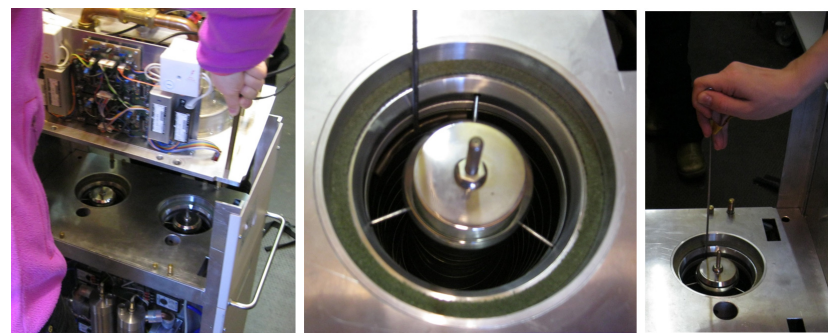

Figure 10. Cleaning electrometer rings by lifting away the sample preconditioning unit (the top part of the NAIS) and using a long cleaning rod to wipe the surface of outer electrode.

the ion and particle number size distributions are similar and form a continuous distribution before and after cleaning.
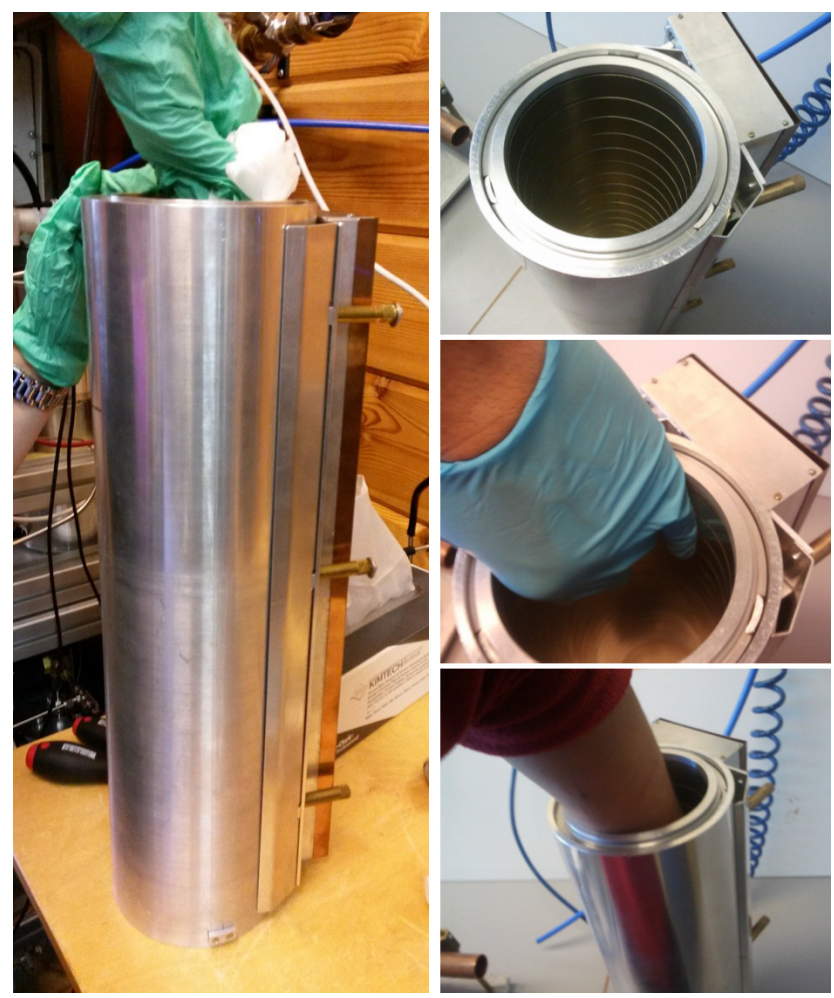

Figure 11. Cleaning electrometer rings by opening the mobility analyzer and wiping with a clean cloth.
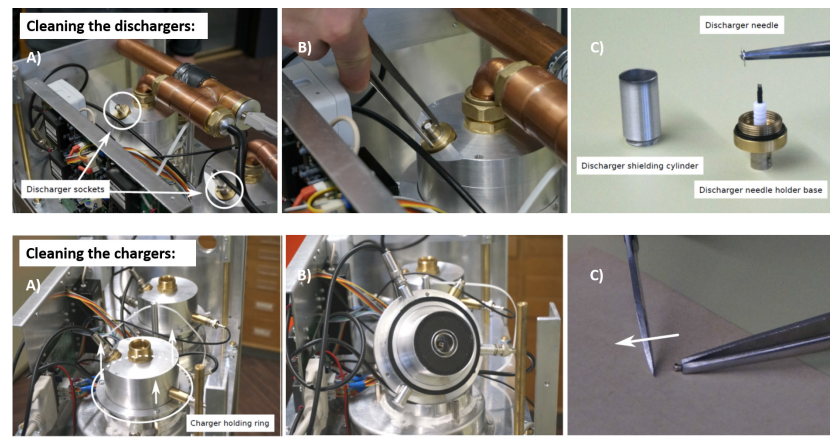

Figure 12. Opening and cleaning the dischargers (upper row) and the chargers (bottom row).

\subsubsection{CRITICAL: cleaning the electrometer rings of the analyzer}

The number concentration of ions and aerosol particles are determined by measuring a current delivered by the flow of charged particles to an electrometer rings. The electrometers are extremely sensitive. The deposition of dirt onto the electrometer ring can deteriorate the signal-to-noise ratio of the electrometer. Dust or fibers that have settled on the electrode may start to form an occasional corona discharge in the electric field of the analyzer. This is the reason why the electrometers facing the bottom inner electrode, which has the highest 

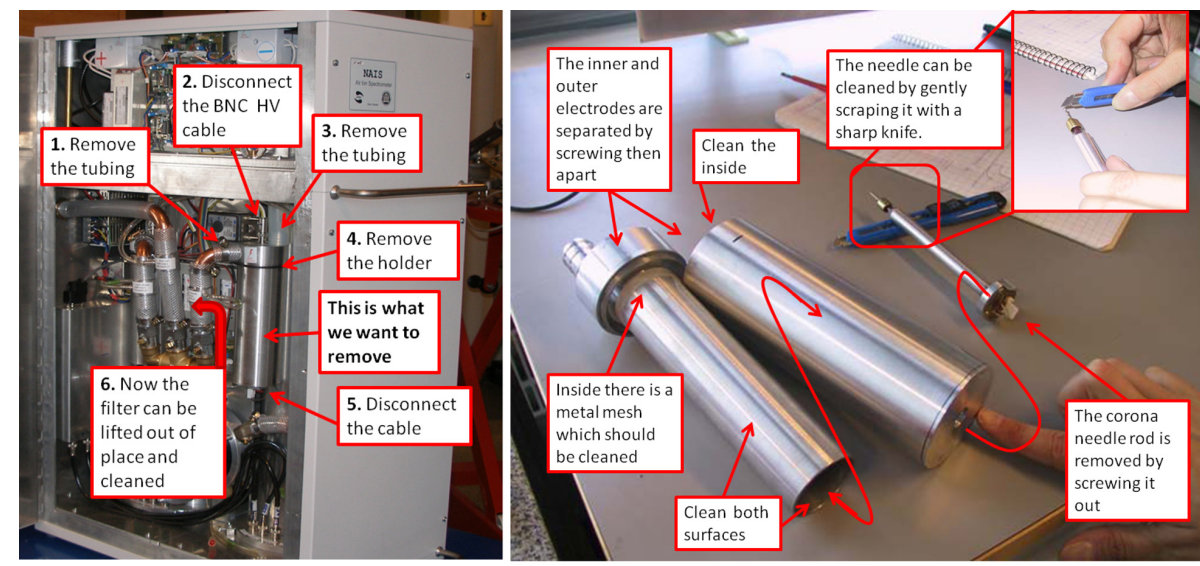

Figure 13. Removing and cleaning the sheath air filters. Some of the newest NAIS's do not have corona needle inside the sheath air filter.

voltage, are the most likely to become noisy (electrometers no. 13-21). We recommend wiping the electrometer rings clean manually when the average current signal of a certain electrometer increases above few tens of fA $\left(10^{-15} \mathrm{~A}\right)$ during the offset measurement mode. See Supplement S1 for details.

\section{Option A: by lifting away the sample preconditioning units}

To clean the electrometer rings without removing and opening the mobility analyzer, remove the top part of the instrument (i.e. sampling preconditioning unit; see Fig. 1). Then use a cleaning rod to clean the mobility analyzer by moving the rod from top to bottom. Figure 10 shows the procedure. Before lifting the top part of the NAIS, ensure that you remove all the nuts holding the plates together and disconnect all the cables coming from the main compartment of the instrument, and disconnect sheath air tubing between the top and bottom part of the NAIS (on both polarities). The top part should be lifted up and placed onto a clean surface, while the open analyzer should be covered to avoid dropping more dirt into it while cleaning. Now the inner and outer electrode of the mobility analyzer (i.e. electrometer rings) can be cleaned with the cleaning rod by moving it up and down inside the analyzer. Avoid scratching the metallic surfaces. The numbering of the electrometers starts from the top to bottom. Remember that the electrometers detecting the smallest charged particles are at the top of the analyzer.

\section{Option B: by opening the mobility analyzer}

To open the mobility analyzer it needs to be lifted away from its position. The outer electrode of the analyzer should be lifted up, and separated from the inner electrode. Supplement S1 shows, in detail, how to clean the analyzers after opening the mobility analyzer. The electrometers are located on the surface of the outer electrode, whereas the inner electrode has the four voltage sectors to generate the electric field. Take care not to scratch the inner electrode against the outer electrode. After the electrodes are separated, it is possible to clean the electrometer rings by wiping with a clean cloth and some strong solvent like alcohol or isopropanol; see Fig. 11. Wiping should be done by starting from the centre of the electrode and moving towards the top. Take particular care to clean the gaps between the electrometer rings as well as their surfaces. Flip the electrode upside down and repeat the operation to clean the bottom electrometers.

\subsubsection{Cleaning or replacing a corona needle}

The charging efficiency of the corona charger can change over time as the electrode (i.e. corona needle/wire) gets worn out. For this reason, the NAIS corona needles need to be cleaned regularly or replaced. To clean the corona needles located in the preconditioning unit's charger or discharger, shown in Fig. 12, or in the sheath air filter, shown in Fig. 13, the corresponding parts of the NAIS need to be opened and the needles removed. As shown in Fig. 14, the corona needle can be cleaned from dirt by gently scraping the tip with a sharp knife or by dissolving the dirt. The corona needles break and bend easily so minimum pressure should be applied. When the cleaning does not restore the charging efficiency, the needle needs to be replaced. When replacing the corona needle, be careful and handle the needle with flat tip tweezers. See Supplement S2 for details.

\subsubsection{Replacing a blower}

A blower needs to be replaced, when the active feedback loop cannot maintain the right volumetric flows for the sample and sheath flows, which leads to wrong sizing of the aerosol particles. The blower must be sealed properly and a leak test should be done to the instrument before determining the flows. For the 1-blower system, the blower sealing should be done using silicone (e.g. Bostik silicone universal) to seal 

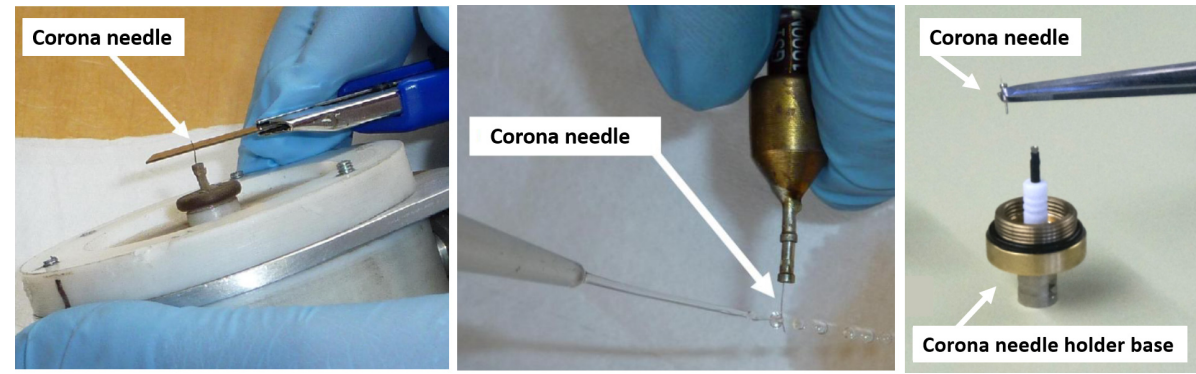

Figure 14. Cleaning the corona needle with a sharp knife (left) or by rinsing with a dissolvent (middle), and replacing a corona needle using tweezers (right)

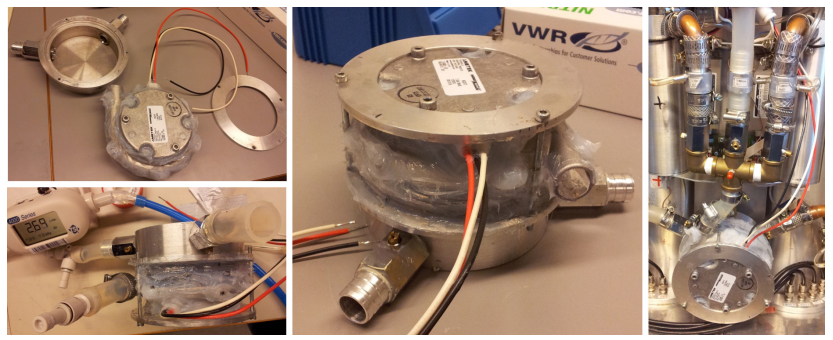

Figure 15. Procedure for replacing a blower for a 1-blower instrument.

both the blower itself and to connect it in a leakproof manner to the metal casing, shown in Fig. 15.

\subsection{Data inversion}

\subsubsection{CRITICAL: electrical mobility to mobility diameter conversion}

The particle diameter is not a well-defined concept at very small sizes or for highly non-spherical particles and agglomerates. We recommend using the electrical mobility equivalent diameter as it can be converted back to the particle electrical mobility, which is the measured quantity by the NAIS. The electrical mobility $\left(Z_{\mathrm{p}}\right)$ to particle diameter $\left(D_{\mathrm{p}}\right)$ conversion should follow the international standard ISO 15900, and use a Millikan-Fuchs equivalent electrical mobility diameter which is based on Stokes' law (Hinds, 1982)

$Z_{\mathrm{p}}=\frac{n e C_{\mathrm{c}}\left(D_{\mathrm{p}}\right)}{3 \pi \eta D_{\mathrm{p}}}$

where $n$ is number of excess elementary charges $e$ carried by the particle, $\eta$ is viscosity of air and $C_{\mathrm{c}}$ is the Cunningham slip correction factor for taking account of relation between particle radius and mean free path $\lambda$ of the gas molecules:

$C_{\mathrm{c}}\left(D_{\mathrm{p}}\right)=1+\frac{2 \lambda}{D_{\mathrm{p}}}\left(1.165+0.483 e^{-0.997 \frac{D_{\mathrm{p}}}{2 \lambda}}\right)$.

Gas pressure and temperature affect viscosity and the mean free path. Typically the particle size and the mean free path are presented as Knudsen number $K_{n}=2 \lambda / D_{\mathrm{p}}$. The constants used in equations follow the ISO15900 standardization as well Kim et al. (2005).

Air viscosity can be written as follows:

$\eta=\eta_{0}\left(\frac{T}{T_{0}}\right)^{\frac{3}{2}}\left(\frac{T_{0}+110.4 \mathrm{~K}}{T+110.4 \mathrm{~K}}\right)$,

where $\eta_{0}=1.83245 \times 10^{-5} \mathrm{~kg} \mathrm{~m}^{-1} \mathrm{~s}^{-1} . T$ is the air temperature and $T_{0}$ is a reference temperature $(296.15 \mathrm{~K})$. On the other hand, the mean free path at a reference temperature $T_{0}=296.15 \mathrm{~K}$ and reference pressure $p_{0}=101.325 \mathrm{kPa}$ is $\lambda_{0}=67.3 \mathrm{~nm}$ and it can be scaled as follows (Allen and Raabe, 1985):

$\lambda=\lambda_{0}\left(\frac{T}{T_{0}}\right)^{2}\left(\frac{p_{0}}{p}\right)\left(\frac{T_{0}+110.4 \mathrm{~K}}{T+110.4 \mathrm{~K}}\right)$.

The classic Millikan equation may be inaccurate for the finest charged nanometer particles and ions (e.g. Tammet, 1995, and references therein). Mäkelä et al. (1996) analyzed phenomena in detail and compared different mobility equivalent diameters. For the NAIS data, the electrical mobility to electrical mobility equivalent diameter conversion is commonly done following the suggestion of Mäkelä et al. (1996) using the Cunningham slip correction factor with $\lambda=64.5 \mathrm{~nm}$ at $296.15 \mathrm{~K}$ and $101.325 \mathrm{kPa}$ :

$C_{\mathrm{c}}\left(D_{\mathrm{p}}\right)=1+\frac{2 \lambda}{D_{\mathrm{p}}}\left(1.246+0.420 e^{-0.87 \frac{D_{\mathrm{p}}}{2 \lambda}}\right)$.

This approach is in excellent agreement with the ISO standard in normal temperature and pressure (NTP) conditions $(293.15 \mathrm{~K}, 1013.25 \mathrm{hPa})$. Note that the geometric diameter (i.e. Tammet's mass diameter; Tammet, 1995), which is related to particle mass, is about $0.3 \mathrm{~nm}$ smaller than the electrical mobility diameter (Mäkelä et al., 1996; Ehn et al., 2011).

\subsubsection{CRITICAL: raw signal - electrometer currents}

The raw signal of the NAIS is calculated from the current $I$ (A) measured by one of the NAIS electrometers, which is 
related to the sampled aerosol concentration $N$ (ions $\mathrm{cm}^{-3}$ ) as follows:

$I=N n_{\mathrm{p}} e Q_{\mathrm{s}}$,

where $n_{\mathrm{p}}$ is the average number of elementary charge units per particle (assumed to be unity), $e=1.6 \times 10^{-19} C$ is the elementary unit of charge, and $Q_{\mathrm{s}}\left(\mathrm{cm}^{3} \mathrm{~s}^{-1}\right)$ is the volumetric sample flow rate passing the electrometer. When the average number of elementary charge units per particle is known, the aerosol concentration can be calculated from Eq. (6).

The NAIS measures all electrometer signals approximately 12 times per second. Data is averaged typically over $1 \mathrm{~s}, 10 \mathrm{~s}$ and measurement cycle (block) periods. The instrument measures a large number of secondary parameters that describe the detailed state of the whole system. The average electrometer signals together with the secondary measurement parameters are stored into record files by the Spectops measurement software.

The average electrometer signals are converted into ion mobility or particle size distributions by the Spectops software and stored in spectra files. The distribution is calculated using the generalized least squares method to find the size or mobility distribution that best matches the measured electrometer currents according to the instrument matrix while taking into account the noise level estimates. The instrument matrix is based on a mathematical model of the instrument that considers particle losses, charging probability (in case of particle mode measurements), electric field and air flow inside the mobility analyzer.

It is important that the user always stores the record files together with the spectra files containing the measured distributions. The secondary measurement parameters stored in the record files are vital for confirming the validity of the measurements and for problem diagnostics with the instrument. The spectra files can be recalculated from the electrometer signals stored in the record files as part of pre-processing and data analysis.

\subsubsection{On the assumption of equilibrium charge distribution}

The sampled particles are assumed to be in charge equilibrium. The particle charging probability is predicted by Fuchs' diffusion charging theory (Fuchs and Sutugin, 1971). At a constant corona-wire current, the aerosol charging depends mainly on the particle size, on the charger ion concentration and on the residence time of the aerosol in the charging region. The product of the latter two is called nt product. The model that performs the NAIS inversion, takes into account measured aerosol volumetric flow rates, particle charging probabilities, size dependent loss factors, and the charging parameter (i.e. nt product). The charging probabilities use a calibrated charging parameter $\alpha=6$, which translates to $\mathrm{nt}=2.22 \times 10^{6}$ for a mobility of $1.5 \mathrm{~cm}^{2} \mathrm{~V}^{-1} \mathrm{~s}^{-1}$.
According to these numbers, $1 \%$ of $1 \mathrm{~nm}$ particles and $5 \%$ of $5 \mathrm{~nm}$ particles are singly charged.

Although the data inversion assumes that the sampled particles are in a charge equilibrium, the unipolar charger does not neutralize the aerosol sample entering the NAIS (McMurry et al., 2009). Thus, if the sample is highly overcharged, this can lead to an overestimation of the ion and particle concentrations.

\subsubsection{CRITICAL: on the assumption of singly charged ions and particles}

In the ion mode, the inversion considers only charged particle mobility. It does not make assumptions about their charging probability or background aerosols. Therefore, it produces a mobility distribution which the user will later convert into a size distribution assuming that all the detected ions are singly charged. To simplify, in ion mode we make an assumption that all charged particles are singly charged. In practice, this means that ion concentrations in the size range from $\sim 20$ to $40 \mathrm{~nm}$ may be overestimated and the shape of the distribution may be distorted as a part of these particles carry more than one charge.

Moreover, Alguacil and Alonso (2006) reported that when using a corona discharge, a substantial fraction of doubly charged particles occur in the particle diameters down to $\sim 15 \mathrm{~nm}$. Therefore, the measurement uncertainty of the NAIS increases above $20 \mathrm{~nm}$ because the corresponding electrometers are also affected by the multiply charged particles with diameters up to $90 \mathrm{~nm}$. Due to the limited mobility the range of the DMA, the data inversion cannot completely account for these effects stemming from larger particles. Therefore, we recommend that the ion and particle number size distributions above $20 \mathrm{~nm}$ should be utilized with caution. One possibility is to merge the number size distribution measured with the NAIS into a distribution measured with, e.g. a differential mobility particle sizer (DMPS, Wiedensohler et al., 2012) in size range from 10 to $1000 \mathrm{~nm}$ to obtain information on the background aerosol population to be used in the data inversion (e.g. Kulmala et al., 2012).

\subsubsection{Instrument function: transfer functions and loss estimation}

A detailed description of the mathematical model of the NAIS is presented in Mirme and Mirme (2013). The instrument response of the NAIS is a set of electric currents that are generated by the flux of ions precipitating on the collecting electrodes. An ion mobility distribution $f(z)$ is linked with the electrometer currents $y_{i}(i=1 \ldots n)$ using the analyzer response function $G(i, z)$ as follows:

$y_{i}=\int[e G(i, z)] f(z) \mathrm{d} z(i=1, \ldots, n)$,

where $e$ is the elementary charge. 
The analyzer transfer function $G(i, z)$ is the response of an electrometer $i$ to a singly charged ion with a mobility of $z$. The function is derived in a straightforward way presented in Mirme and Mirme (2013) and it is verified by calibration measurements in the ions mode. Diffusion losses for the sampled particles inside the instrument are estimated by fitting a diffusion length parameter of the instrument model to the ion mode calibration results. The diffusion and electrostatic losses in the sampling lines prior to the instrument should be taken into account by the user.

During particles measurements, the corona charger is active. The instrument response in the particles mode includes the charging probability function $P(q, r)$ :

$$
\begin{aligned}
y_{i}= & \int\left[e \sum_{q} q G(i, z(r, q)) P(q, r)\right] f(r) \mathrm{d} r \\
& (i=1, \ldots, n),
\end{aligned}
$$

where $f(r)$ is the particle size distribution and $P(q, r)$ is the probability that a particle with a radius of $r$ carries $q$ elementary charges.

The analyzer transfer function $G(i, z)$ is identical for both ions and particles measurements. The charging probability function $P(q, r)$ is based on a theoretical charging model. The function is adjusted and verified using calibration measurements in the particles mode.

The data inversion finds an approximate ion mobility distribution $f(z)$ or particle size distribution $f(r)$ that best satisfies Eq. (7) or (8). The distributions are estimated as a sum of predefined elementary distributions $F_{i}(r)$.

$f(r)=\sum_{j} \phi_{i} \cdot F_{i}(r)$.

This allows to transform Eq. (7) or (8) to an equivalent matrix form as follows:

$y_{i}=\sum_{j} \mathbf{H}_{i j} \cdot \boldsymbol{\phi}_{j}(i=1, \ldots, n)$,

where $\mathbf{H}$ is the instrument matrix and $H_{i j}$ determines the response of the electrometer $i$ to the predefined distribution $F_{i}(r)$. The data inversion procedure solves the matrix Eq. (10) for the spectrum vector $\boldsymbol{\phi}_{j}$ and calculates the size or mobility distribution estimate using Eq. (6).

The ratio of sample flow to total analyzer flow is about $1: 3$ for the NAIS, which is quite large and therefore even perfectly monomobile particles will have a response on several electrometers. For the particles with diameters above $20 \mathrm{~nm}$ the probability of acquiring more than one elementary charge in the corona charger is non-negligible. Hence the electrometer response for the larger particles becomes even wider. This also means that the measured electrometer signal may be a combination of by both singly charged smaller particles and multiply charged larger particles with the same mobility.

The multiply charged particles do not require special treatment in the data inversion. They are naturally included in the calculated response of the electrometers, i.e. the instrument matrix. However, the uncertainty of the measurement results gradually increases for particle sizes above $20 \mathrm{~nm}$ because the electrometer responses become less distinguishable for the larger particles and because a gradually larger portion of the response will be lost beyond the mobility range of the NAIS.

\section{Additional particle losses}

The electrostatic losses inside the corona charger during charging process lead to underestimation of the particle concentration (Alonso et al., 2006; Huang and Alonso, 2011). The diffusion losses decrease and electrostatic loss increase as the charger voltage is increased, whereas charging efficiency increases with particle size and charger voltage. Electrostatic loss of small particles increases with decreasing particle diameter. The electrostatic losses in the sampling lines prior to the instrument should be taken into account by the user.

\subsection{Data processing}

To obtain the aerosol size distribution, $\mathrm{d} N / \mathrm{d}\left(\log _{10} D_{\mathrm{p}}\right)$, from the current signal caused by charged particles and the voltages applied in the classification, the data inversion take into account the charge distribution of the aerosol particles, the flows rates, the DMA transfer functions, the detection efficiency of the detector and size dependent losses in the instrument. In the ion mode, the Spectops inversion algorithm converts raw signal from 21 electrometers into 28 normalized mobility fractions, whereas in the particle mode, the raw data is converted into 29 size fractions. In the data processing the user should do the following quality checks and corrections for the NAIS data.

\subsubsection{Data cleaning and quality check}

After the data collection and prior to the data analysis, the data should be quality controlled. The bad data should be removed from the final data. Figure 16 illustrates some examples of typical faulty spectra and the data needed to be removed. Data quality checks and criteria, which should be fulfilled for the ion number size distributions, are the following: (1) negative and positive ion number size distribution agree visually (a similar distinct shape for number size distributions in both polarities), (2) size distribution has a continuous cluster ion mode visible in both polarities with a mode peak at $\sim 1 \mathrm{~nm}$; see Fig. 16b, (3) when looking at the negative ion size distribution, the mean diameter of cluster ion mode should be slightly smaller compared to positive cluster ions (typically one channel difference between the peaks for the polarities), (4) in the number size distribution plots, the smallest of Aitken mode charged particles should be visible and have a diurnal variation at $25-42 \mathrm{~nm}$ size range, and (5) time series of total ion number concentration between polarities should agree within 10-20\%, which should apply to 
(a)

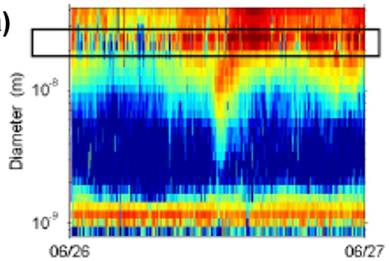

(b)

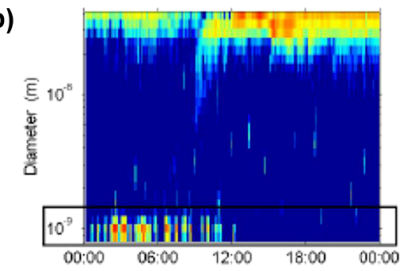

(c)

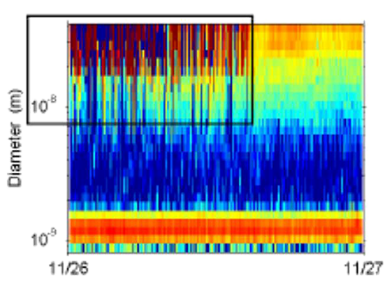

(d)

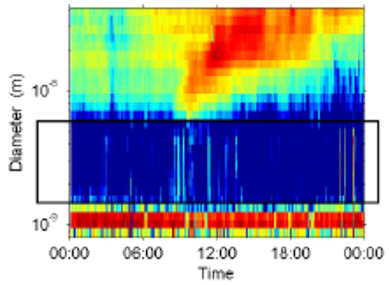

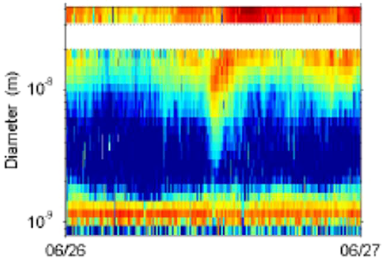
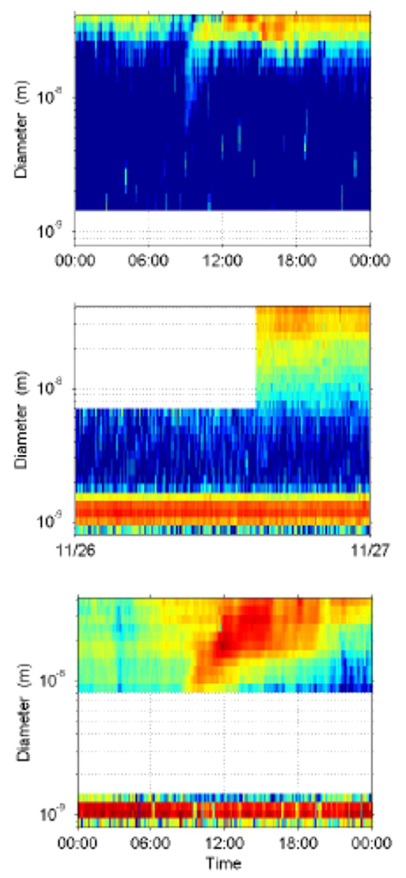

Figure 16. Typical faulty ion number size distributions before (left column, problematic area boxed) and after (right column) cleaning and quality checks. The bad or missing data was selected and replaced with -999.99 using a MATLAB script. The faulty data was caused by (a) continuously noisy electrometer, (b) bad grounding at the top of the DMA (partly missing cluster ions), (c) dirt in the bottom of the DMA (high noise), and (d) classifying electric field inside the DMA as not correct due to a bad BNC (Bayonet-NeillConcelman) cable connection (intermediate ions missing).

small, intermediate ions and large ion concentrations as well, and (6) when intermediate ions are observed, make sure that the size distribution does not have any gaps due to instrument malfunction; see Fig. 16d.

The primary data quality checks for the particle number size distributions are similar as for the ion data. In addition, check that the corona-charger-generated ions do not dominate the particle spectra due to inadequate post-filter settings: (1) the $2-3 \mathrm{~nm}$ particle concentrations should remain in a range of $\sim 200-700 \mathrm{~cm}^{-3}$, when no new particle formation event is taking place to maintain optimal post-filter setting, (2) determine the smallest detectable size using both positive and negative polarities (see Sect. 3.7.4), and (3) select the preferred polarity to give the final data for measured particle number size distribution (Sect. 3.7.5).

If possible the ion and particle data measured with the NAIS should be crosschecked with the data from additional instruments. The data quality check for the offset mode: electrometer currents during offset measurements should not exceed $\pm 10 \mathrm{fA}$.

\subsubsection{Ion data: converting from mobility distribution to size distributions}

In the ion mode, the Spectops inversion algorithm converts signal from 21 electrometer signals into 28 normalized ion mobility distributions, $\mathrm{d} N / \mathrm{d}\left(\log _{10} Z_{\mathrm{p}}\right)$, which the user has to convert into ion size distributions, $\mathrm{d} N / \mathrm{d}\left(\log _{10} D_{\mathrm{p}}\right)$. We recommend doing the mobility to diameter conversion using the Millikan-Fuchs equivalent mobility diameters introduced in Sect. 3.6.1.

To do this, the user should follow steps: (1) Open the spectra data files to get the geometric means of all 28 mobility fractions and calculate the lower and upper mobility limits for each mobility fraction. (2) Calculate the $\mathrm{d}\left(\log _{10} Z_{\mathrm{p}}\right)$ for all the mobility fractions using these limits. (3) Calculate the absolute number concentration for each mobility fraction starting from the normalized ion mobility fractions: $\left(\mathrm{d} N / \mathrm{d}\left(\log _{10} Z_{\mathrm{p}}\right) \times \mathrm{d}\left(\log _{10} Z_{\mathrm{p}}\right)=\mathrm{d} N\right.$. (4) Calculate the corresponding mobility diameters for each mobility fraction limits by determining the lower and upper limiting diameters, and calculate the $\mathrm{d}\left(\log _{10} D_{\mathrm{p}}\right)$ for all size fractions. (5) Normalize the absolute concentrations using the determined size fractions: $\mathrm{d} N \times\left(1 / \mathrm{d}\left(\log _{10} D_{\mathrm{p}}\right)\right)=\mathrm{d} N / \mathrm{d}\left(\log _{10} D_{\mathrm{p}}\right)$.

\subsubsection{CRITICAL: correction for diffusional losses at sampling line}

Diffusion losses inside the sampling lines prior to the instrument; see Fig. 7 (upper panel), should be taken into account by post-processing of the data. The particle losses by diffusion in a straight inlet line can be described by calculating a size-dependent particle penetration (Hinds, 1982). In laminar flow, these losses depend only on the line length, the flow rate through the line, and the particle size. In cases that bends cannot be avoided in the sampling pipe, the size-depended particle penetration can be calculated according to Wang et al. (2002).

\subsubsection{Particle data: determining the smallest detectable size}

In the particle mode, the raw data is typically converted into 29 particle size distributions, $\mathrm{d} N / \mathrm{d}\left(\log 10 D_{\mathrm{p}}\right)$, by the Spectops software. During the particle mode measurements, the corona-generated ions complicate the particle detection as the measurement size range overlaps the size range of the charger ions. The positive and negative corona-generated ions are smaller than 1.8 and $1.6 \mathrm{~nm}$, respectively, which results in the lower detection limit of approximately $2 \mathrm{~nm}$ for the NAIS particle measurements (Manninen et al., 2011). 
Therefore, the particles below about $2 \mathrm{~nm}$ cannot be reliably distinguished from the corona-generated ions. Typically, the lowest detection limit for the NAIS in the particle mode is between 2 and $3 \mathrm{~nm}$ depending on the corona voltage and on the properties and composition of carrier gas (environmental conditions). It is important to notice that the lowest detection limit of the NAIS varies according to the environmental conditions (Manninen et al., 2011). The lowest detectable size of the NAIS in particle mode should be checked on regular basis, at least separately for different seasons.

During subsequent data processing the corona-generated ions below the lowest detection limit should be always cut out of the particle number size distribution. The lowest detection of the NAIS is equal to the upper edge of the corona ion size distribution which is illustrated with the gray shaded area in Fig. 3. The determination of the lower detection limit should be done always when no new particle formation (i.e. natural cluster activation and growth) is taking place. If possible, after removing the corona ions from the particle number size distribution, the particle concentrations in the 2$3 \mathrm{~nm}$ range should remain in a concentration range of $\sim 200$ $700 \mathrm{~cm}^{-3}$ to make sure that not all charged particles are cut out together with the corona-generated ions.

\subsubsection{Particle data: selecting preferred polarity of corona discharging}

Due to the design of the instrument, the particle spectra (i.e. particle number size distribution) is measured with both positive and negative corona charging. Ideally the distributions should be identical. A large and a persistent difference may indicate a problem with the measurements. We recommend giving only one particle spectra in the final processed data to avoid misunderstanding. Thus, the user needs to decide on the preferred polarity on the particle data, which is reported as the final particle number size distribution. Typically, the preferred polarity is chosen with two main criteria: (1) the polarity which has lower background level of the coronacharger ions extending to 2-3 nm size range (which is considered the lowest detection limit of the NAIS in particle mode); (2) the polarity, which shows no short-term fluctuation over time (i.e. corona-charger ion background stays same level over a diurnal cycle). (3) The small corona-charger ion background $\left(\sim 10^{2}\right)$ should be visible at $2-3 \mathrm{~nm}$ to be sure that the particles in the aerosol sample are not filtered with the electric post-filter.

\section{Troubleshooting}

The troubleshooting, in Table 2 lists how to recognize a faulty spectrum, identify potential problems and their corresponding solutions ranging from the instrumental to software issues. For further NAIS problem solving and identifying symptoms while operation; see Supplement S2.

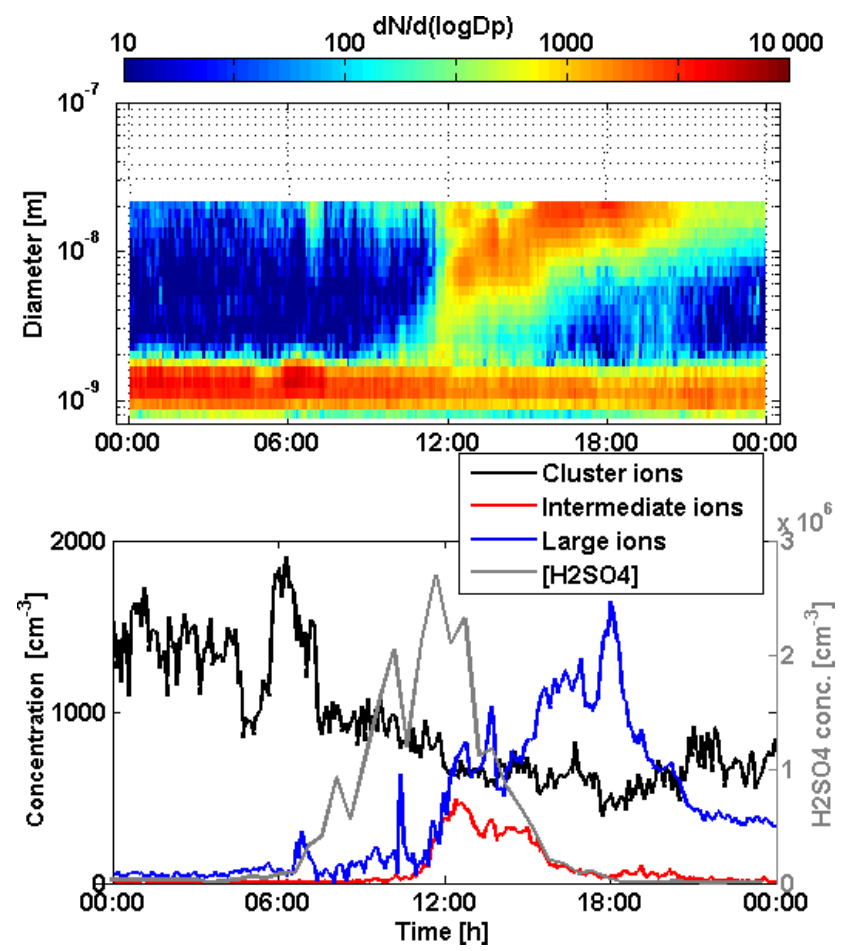

Figure 17. An exemplary negative ion number size distribution during a new particle formation measured with the NAIS (upper panel), and concentration of negative cluster ions $(0.8-2.0 \mathrm{~nm})$, intermediate ions $(2.0-7.0 \mathrm{~nm})$, large ions $(7.0-20 \mathrm{~nm})$ and gas phase sulfuric acid (lower panel) on 5 May 2007 in Hyytiälä.

\section{Anticipated results}

The list of locations and altitudes, where frequent aerosol particle formation has been observed, is still growing as new measurement campaigns are organized and field sites are established. A recent review is presented in Hirsikko et al. (2011).

\subsection{Direct observation of atmospheric particle formation and growth}

The ion spectrometer measurements performed within the EUCAARI project (Kerminen et al., 2010; Kulmala et al., 2011) present, so far, the most comprehensive effort to experimentally characterize nucleation and growth of atmospheric molecular clusters and nanoparticles at ground-based observation sites on a continental scale (Manninen et al., 2010). The atmospheric particle formation data analysis routines for the NAIS data, e.g. estimating the contribution of ions to particle formation, calculating the cluster ion and aerosol particle formation and growth rates, and the ion-ion recombination rates, is described in details in separate procedure article (Kulmala et al., 2012). 
Table 2. Troubleshooting.

Solution

Particle/ion distribution issues:

\begin{tabular}{|c|c|}
\hline Problem & Possible reason \\
\hline \multicolumn{2}{|l|}{ Particle/ion distribution issues: } \\
\hline $\begin{array}{l}\text { No ions observed. } \\
\text { Ion number size distribution spectra in } \\
\text { Spectops screen is blue. }\end{array}$ & $\begin{array}{l}\text { Instrument or inlet is not properly } \\
\text { grounded or inlet tube is too long. } \\
\text { Offset measurements have a problem. }\end{array}$ \\
\hline $\begin{array}{l}\text { The particle or ion number size spectro- } \\
\text { gram has a continuous or intermittent high } \\
\text { concentration as a function of time at a } \\
\text { certain size or mobility indicated with a } \\
\text { red stripe in the data. } \\
\text { One of the electrometers is saturated con- } \\
\text { tinuously. }\end{array}$ & $\begin{array}{l}\text { One or more electrometers is noisy or } \\
\text { have a high offset current due to settled } \\
\text { dirt or fibers inside the analyzer. }\end{array}$ \\
\hline $\begin{array}{l}\text { No cluster (small) ions detected and a high } \\
\text { concentration peak at around } 5 \mathrm{~nm} \text {. Other- } \\
\text { wise ion spectra look normal. }\end{array}$ & $\begin{array}{l}\text { The top part of the inner electrode of the } \\
\text { DMA is short circuited to zero poten- } \\
\text { tial. There is no electric field to classify } \\
\text { small ions. This happens, when the isola- } \\
\text { tion of one of the three centring rods of the } \\
\text { "cartwheel" is damaged. }\end{array}$ \\
\hline
\end{tabular}

Ion number size distribution spectra in

Spectops screen is blue.

The particle or ion number size spectrogram has a continuous or intermittent high concentration as a function of time at a concentration peak at around $5 \mathrm{~nm}$. Otherwise ion spectra look normal. itive and negative polarity are not corresponding (not matching), Sect. 3.2.2).
Airflows are not correct. Instrument might have a leak.

The preconditioning unit has a problem: cables disconnected or switched.
Make proper grounding using a metallic wire. Shorten the inlet.

To test the inlet losses, remove the inlet temporarily (see Sect. 3.3.1).

Clean the corresponding electrometer rings of that polarity (Sect. 3.5.3).

Note: Opening the mobility analyzer and cleaning it can end up making it dirtier, if not done in a clean environment.

Remove the preconditioning unit. Open the top part of the DMA and check the isolation between the inner and outer electrode of the DMA. Isolation is created with a round metallic connector (check that 3 rubber rings around the wires are on their place).

Note, during transportation and routine cleaning these rubber rings move easily.

Check instrument software warnings related to sample and sheath flows.

See the instructions for general "Airflow related issues" below.

Check that all the plugs connect properly to the correct sockets in the preconditioning unit.

Check software warnings related to chargers and filters.

The electric fields are not symmetric on Check DMA voltages (Sect. 3.1.2). both polarities.

Corona charger ions are not removed Adjust the post-filter voltage (Sect. 3.4.4). properly by the post-filter.

Total particle spectra appears continuously red in colour at Spectops screen with very high concentrations $\left(\sim 10^{5}-\right.$ $\left.10^{6}\right)$.

The upper edge of the corona charger ions is larger than $3 \mathrm{~nm}$ in particle mode (Sect. 3.7.4).

Ion and particle spectra in Spectops is red for few hours but instrument recovers itself.

Note: High concentrations more in negative polarity.

There are random vertical stripes in the spectrograms.
Especially during rain and snow, some water might get inside instrument settle on the electrometers.
Clean and dry the instrument (see Sects. 3.5.1-3.5.2 and 3.5.5).
The central electrode voltage source is not stable. This induces simultaneous and identical fluctuations in many neighbouring electrometers. 
Table 2. Continued.

\begin{tabular}{|c|c|c|}
\hline Problem & Possible reason & Solution \\
\hline \multicolumn{3}{|l|}{ Preconditioning unit issues: } \\
\hline $\begin{array}{l}\text { A discharger or charger current control } \\
\text { voltage is near maximum. }\end{array}$ & $\begin{array}{l}\text { A corona charger needle is dirty. The } \\
\text { corona needle voltage is near maximum, } \\
\text { but the charger current is still insufficient. }\end{array}$ & $\begin{array}{l}\text { Clean or replace the corresponding corona } \\
\text { needle (Sect. 3.5.5). }\end{array}$ \\
\hline $\begin{array}{l}\text { Charger current fluctuates or decreases } \\
\text { rapidly. }\end{array}$ & Corona charger needle is dirty. & \\
\hline \multirow[t]{2}{*}{$\begin{array}{l}\text { A discharger or charger current control } \\
\text { voltage is near minimum. }\end{array}$} & $\begin{array}{l}\text { Preconditioning unit cables may be incor- } \\
\text { rectly connected. }\end{array}$ & $\begin{array}{l}\text { Check that all the plugs connect properly } \\
\text { to the correct sockets in the precondition- } \\
\text { ing unit. }\end{array}$ \\
\hline & $\begin{array}{l}\text { Leakage currents due to humidity prevent } \\
\text { correct charger current measurement. }\end{array}$ & $\begin{array}{l}\text { Run the instrument in dry conditions for } \\
\text { at least } 6 \mathrm{~h} \text {. }\end{array}$ \\
\hline \multicolumn{3}{|l|}{ Differential mobility analyser (DMA) issues: } \\
\hline \multirow[t]{2}{*}{ An analyzer voltage is too low. } & $\begin{array}{l}\text { The voltages need } 5-10 \mathrm{~min} \text { to stabilize } \\
\text { after power-on. }\end{array}$ & Wait for the instrument to warm up. \\
\hline & An analyzer voltage source is broken. & $\begin{array}{l}\text { Disconnect the corresponding analyzer } \\
\text { voltage plug and measure the voltage with } \\
\text { a separate voltmeter. Contact Airel Ltd. }\end{array}$ \\
\hline An analyzer voltage is too high. & $\begin{array}{l}\text { The voltage sources may drift slowly as } \\
\text { they age and need readjustment. }\end{array}$ & $\begin{array}{l}\text { Contact Airel Ltd. and send the power } \\
\text { source for the readjustment. }\end{array}$ \\
\hline \multicolumn{3}{|l|}{ Electrometer issues: } \\
\hline $\begin{array}{l}\text { An electrometer current is missing in } \\
\text { the electrometer signal table in Spectops } \\
\text { screen. }\end{array}$ & $\begin{array}{l}\text { The electrometer is constantly saturated } \\
\text { due to a dirty electrometer. }\end{array}$ & Clean the analyzer (see Sect. 3.5.3). \\
\hline \multirow[t]{3}{*}{$\begin{array}{l}\text { The raw signal of an electrometer is zero } \\
\text { in all operating modes while neighbouring } \\
\text { electrometers show signal. }\end{array}$} & $\begin{array}{l}\text { The electrometer has a bad contact to the } \\
\text { electrode. }\end{array}$ & $\begin{array}{l}\text { Take the electrometer out and put it back. } \\
\text { Note: Some instruments have the test } \\
\text { peaks screwed to the analyzer and this is- } \\
\text { sue is not relevant. }\end{array}$ \\
\hline & $\begin{array}{l}\text { The electrometer has a bad connection to } \\
\text { the data acquisition system. }\end{array}$ & $\begin{array}{l}\text { Take the electrometer out, disconnect and } \\
\text { reconnect the plug, put the electrometer } \\
\text { back in. }\end{array}$ \\
\hline & The electrometer is broken. & $\begin{array}{l}\text { Replace the electrometer. } \\
\text { To confirm the issue, swap the electrome- } \\
\text { ter with another in the same instrument. }\end{array}$ \\
\hline
\end{tabular}

\subsubsection{Cluster ions, intermediate ions, and large ions, i.e. charged particles}

Charged particles are divided into small ions $\left(1.3-0.5 \mathrm{~cm}^{2} \mathrm{~V}^{-1} \mathrm{~s}^{-1}\right), \quad$ intermediate ions (0.5$\left.0.034 \mathrm{~cm}^{2} \mathrm{~V}^{-1} \mathrm{~s}^{-1}\right)$, and large ions (0.034$\left.0.0042 \mathrm{~cm}^{2} \mathrm{~V}^{-1} \mathrm{~s}^{-1}\right)$, which correspond to mobility diameters of $0.8-2,2-7$ and 7-20 nm, respectively (Hõrrak et al., 2001). As can be seen from Fig. 17, the ion number size distribution and time series of ion concentration measured with the NAIS has a distinct shape during new particle formation. The concentration of the small air ions in the atmosphere is determined by competition between production and loss processes (e.g. Israël, 1970; Hirsikko et al., 2011). The small ions i.e. cluster ions are detected in all environmental conditions, where they have been measured with the ion spectrometer varying from extremely polluted areas (e.g. Backman et al., 2012; Herrmann et al., 2014) to extremely clean environments (Virkkula et al., 2007) as well as from the lower troposphere to the free troposphere (e.g. Manninen et al., 2010; Mirme et al., 2010; Rose et al., 2015). The only exception where no cluster ions were observed is when measured inside a cloud (Lihavainen et al., 2007) or during a rapid, extreme increase in particle 
Table 2. Continued.

\begin{tabular}{|c|c|c|}
\hline Problem & Possible reason & Solution \\
\hline \multicolumn{3}{|l|}{ Airflow issues: } \\
\hline $\begin{array}{l}\text { Instrument inlet and outlet flow are not } \\
\text { equal. }\end{array}$ & $\begin{array}{l}\text { Instrument has a leak. } \\
\text { Note: Large leaks you can feel with a wet } \\
\text { finger or use liquid leak detectors (e.g. } \\
\text { Snoop Liquid Leak Detector, Swagelok) if } \\
\text { leak is on overpressure side. Single, small } \\
\text { leaks are difficult to detect. }\end{array}$ & $\begin{array}{l}\text { Check all the tubing and connectors for a } \\
\text { leak. If needed open the whole instrument } \\
\text { and reconnect all parts carefully. Pay at- } \\
\text { tention to the O-ring seals. } \\
\text { Also see the instructions for general "Air- } \\
\text { flow related issues". }\end{array}$ \\
\hline $\begin{array}{l}\text { The blower is making a loud noise } \\
\text { in the 1-blower system or the blower } \\
\text { speed is unstable or decreasing slowly } \\
\left(>100 \mathrm{ccm} \mathrm{s}^{-1} \text { in a day). }\right.\end{array}$ & $\begin{array}{l}\text { The blower soon stops working as it is } \\
\text { worn-out. }\end{array}$ & $\begin{array}{l}\text { Replace the blower (in the 1-blower sys- } \\
\text { tems); see Sect. 3.5.4. }\end{array}$ \\
\hline A flow control voltage is near maximum. & $\begin{array}{l}\text { A blower is unable to provide the required } \\
\text { flow rate or } \\
\text { a flow sensor is incorrectly connected or } \\
\text { broken. }\end{array}$ & $\begin{array}{l}\text { See instructions for general "Airflow re- } \\
\text { lated issues". If everything else is ok the } \\
\text { blower may be near end of life and re- } \\
\text { quires to be replaced. }\end{array}$ \\
\hline \multicolumn{3}{|l|}{ Software issues: } \\
\hline $\begin{array}{l}\text { The particle and ion spectra are not up- } \\
\text { dated to the Spectops screen. }\end{array}$ & $\begin{array}{l}\text { Spectops displays only the selected spec- } \\
\text { tra. }\end{array}$ & Click "Show latest" icon on the task bar. \\
\hline $\begin{array}{l}\text { After installing the software to a new com- } \\
\text { puter, an unidentified communication er- } \\
\text { ror forbids the measurements. }\end{array}$ & $\begin{array}{l}\text { Spectops is not able to connect to the } \\
\text { NAIS. }\end{array}$ & $\begin{array}{l}\text { Note that when the COM-port number } \\
\text { has two digits, you need to add symbols } \\
\backslash \backslash . \backslash \text { in front of it when writing the infor- } \\
\text { mation to a configuration file; e.g. write } \\
\text { " } \backslash \backslash . \backslash \text { COM12". }\end{array}$ \\
\hline
\end{tabular}

number concentration (Jayaratne et al., 2015). On the other hand, the intermediate ions are a strong indicator for the secondary aerosol formation in various environments (Dos Santos et al., 2015; Leino et al., 2016), whereas the large ions represent the naturally charged fraction of Aitken and accumulation mode particles.

Ionization of air molecules (e.g. $\mathrm{N}_{2}$ and $\mathrm{O}_{2}$ ) produces primary air ions: positive ions and free electrons. The primary ions undergo rapid chemical reactions, getting neutralized and charged again, and become small ions in less than a second from their formation (Hõrrak, 2001). To avoid misunderstandings, it should be noted that these primary ions are not detected by the NAIS as their electrical mobility is too high to be classified with the NAIS and their lifetime is too short for the detection with the current version of the instrument.

\subsubsection{Neutral clusters and total aerosol particles}

The lowest detection limit for the NAIS in the particle mode is approximately $2 \mathrm{~nm}$ due to overlapping corona-charger ions (Asmi et al., 2009; Manninen et al., 2011). Thus, the NAIS is not able to detect the pool of stable neutral clusters at sub-2 nm (Kulmala et al., 2013). The NAIS can detect only a "shoulder" of this neutral cluster pool. The NAIS in a very capable tool for detecting the newly formed particle already at the $2-3 \mathrm{~nm}$ size range depending on the post-filter settings.
As an example, the time series of 2-3 and 3-6 nm particle concentrations on new particle formation day are shown in Fig. 18. In the particle mode, the NAIS overestimates the total particle number concentrations by a factor of 2-4 (Manninen et al., 2009; Gagné et al., 2011). The quantitative agreement improves at conditions representing particle formation bursts when higher particle concentrations are typically observed in the overlapping size range (nucleation mode). As seen in Fig. 19, merging particle number size distributions measured with the NAIS $(2.5-40 \mathrm{~nm})$ and a differential mobility particle sizer (DMPS, 40-1000 nm) without any additional fitting highlights the problem at $20-40 \mathrm{~nm}$ range where the agreement is poor, as the NAIS overestimates particle concentrations. Therefore, we recommend using the particle spectra measured with the NAIS up to $20 \mathrm{~nm}$.

\subsubsection{Contribution of ions to aerosol processes}

Neutral particle formation seems to dominate over ioninduced and ion-recombined nucleation, at least in the continental boundary layer (Lovejoy et al., 2004; Manninen et al., 2009, 2010; Zhang et al., 2012; Kulmala et al., 2013). The results obtained from the NAIS particle and ion measurements agree well with separate independent measurements performed with other electrical mobility spectrometer (e.g. Gagné et al., 2011) and condensation-based tech- 

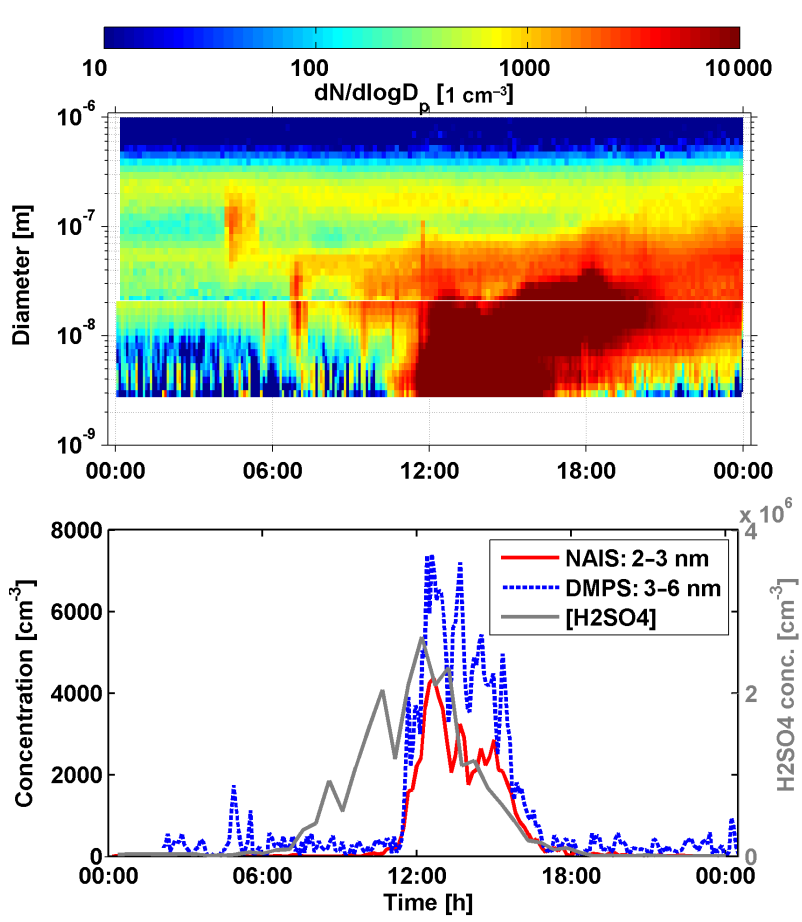

Figure 18. Example of a particle size distribution measured with the NAIS in the size range $2.5-20 \mathrm{~nm}$ and with the DMPS in the size range $20-1000 \mathrm{~nm}$ on 5 May 2007 in Hyytiälä (upper panel), and concentrations of $2-3 \mathrm{~nm}$ particles measured with the NAIS, 3-6 $\mathrm{nm}$ particles with the DMPS, and sulphuric acid (lower panel).

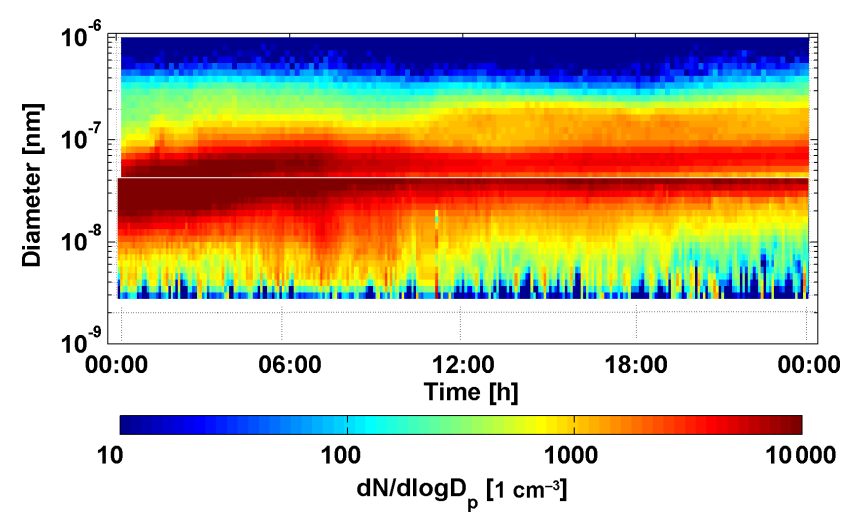

Figure 19. Merging particle size distributions measured with the NAIS in the size range $2.5-40 \mathrm{~nm}$ and with the DMPS in the size range 40-1000 nm on 23 April 2007 in Hyytiälä, Finland.

niques (Lehtipalo et al., 2009, 2010; Kulmala et al., 2013; Rose et al., 2015). The atmospheric ions participate in the initial steps of the new particle formation, although their contribution has been shown to be minor in the boundary layer (e.g. Kulmala et al., 2013). The highest atmospheric particle formation rates are observed at the most polluted sites, where the role of ions was the least pronounced (Manninen et al., 2010). Furthermore, an increase of particle growth rate (a)
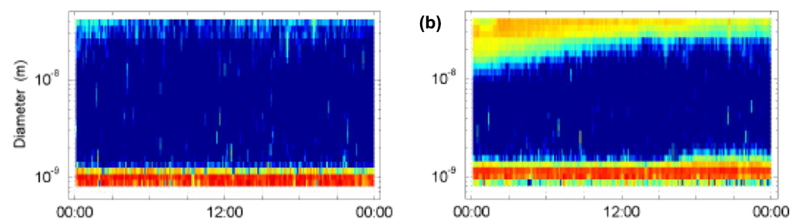

(c)
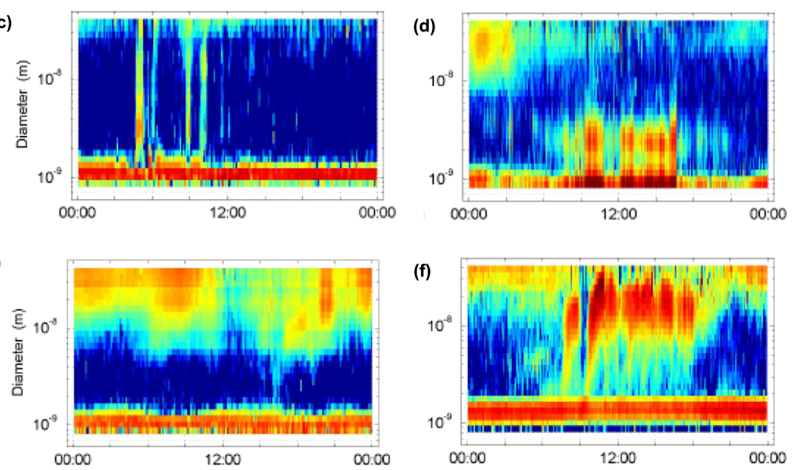

(g)

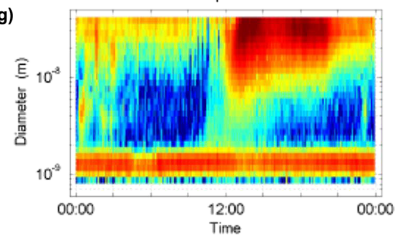

Figure 20. Typical negative ion number size distribution measured with the ion spectrometer in different environments and conditions: (a) no nucleation mode particles, just cluster ions observed in $\mathrm{Fi}$ nokalia on 17 October 2008; (b) lower edge of Aitken mode particles and cluster ions observed in Finokalia on 25 October 2008; (c) intermediate ion bursts observed during heavy rain in Finokalia on 28 December 2008; (d) intermediate ions observed during snow storm in Jungfraujoch on 28 November 2008; (e) undefined particle formation in Cabauw on 15 September 2008; (f) changes in air mass and particle formation in Melpitz on 3 August 2008; (g) regional particle formation in Melpitz on 13 April 2009; and (h) local new particle formation plume in Mace Head on 16 October 2008.

with size suggests that enhancement of the growth by ions is negligible (Yli-Juuti et al., 2011).

\subsection{Typical number size distributions in different environments}

It can be noted from Fig. 20 that typical atmospheric ion and particle distributions measured with the NAIS varies much from a regional new particle event day to a very clean day, when the cluster ions are the most dominant feature in the ion distribution between 0.8 and $42 \mathrm{~nm}$. A closer look at the particle formation, in Fig. $20 \mathrm{f}-\mathrm{h}$, reveals that the nucleation bursts are usually observed during daytime and mostly starting before noon. Based on the visual shape of the time series of the number size distribution, several nucleation event types have been characterized (Hirsikko et al., 2007; Manninen et al., 2010); see Fig. 20 for examples. 


\subsection{Additional value of the NAIS measurements}

\subsubsection{Parameterized ion and particle formation and growth processes}

By conducting measurements according to the work presented here, it is possible to develop simple yet sufficiently accurate nucleation parameterizations for large-scale atmospheric modelling. The secondary aerosol formation includes the production of nanometer-sized clusters from atmospheric vapours and the growth of these clusters to larger particles. One dynamic process modifying the size distributions of neutral and charged clusters is ion-ion recombination, which was parameterized by Kontkanen et al. (2013). Nieminen et al. (2011) derived a parameterization for the ion-induced nucleation or, more precisely, for the formation rate of charged $2 \mathrm{~nm}$ particles. In addition, it is important to predict nanoparticle growth accurately in order to reliably estimate the atmospheric cloud condensation nuclei concentrations. Häkkinen et al. (2013) introduced a semi-empirical parameterization for sub- $20 \mathrm{~nm}$ particle growth that distributes secondary organics to the nanoparticles according to their size and is therefore able to reproduce particle growth observed in the atmosphere. All semi-empirical parameterizations described here are based on extensive NAIS datasets that enable to test how well the parameterization captures the seasonal cycle of the modelled parameters and to determine the required weighing factors in different environments. Leppä et al. (2009) introduced an aerosol dynamical box model, which includes basic dynamical processes (e.g. condensation, coagulation and losses by deposition) as well as ion-aerosol attachment and ion-ion recombination. This model was validated and constrained against the NAIS data.

\subsubsection{Connection to atmospheric electricity parameters}

Small ions are almost always present in the air and are responsible for the atmospheric electrical conductivity (e.g. Harrison and Carslaw, 2003). The early research of air ions was mainly focused on atmospheric electricity to study, e.g. air quality (Israël, 1970). Tammet et al. (2009) suggested that the air ions and the atmospheric electric field controlling the migration of ions should be considered, when discussing the formation of primary and secondary particles. Air (polar) conductivity can be calculated directly from the ion number size distributions measured by the NAIS, in addition to reporting the concentration of small, intermediate, and large ions, and the average small ion mobility.

\section{Discussion and conclusions}

We work towards a better understanding the formation and growth mechanisms of aerosol particles using experimental observations. The first steps to understand the role of ions and particles in the global climate are to understand where, when and why the nucleation mode particles are formed. The current level of understanding the aerosol effects leads to large uncertainties in global climate model predictions (IPCC, 2013). Thus, the current aerosol process models need to be improved to capture the dynamics at sub- $20 \mathrm{~nm}$ size range. To constrain and validate these models, reliable field observations are needed. Here we aim to provide tools to harmonize the measurements performed with the NAIS, leading to comparable results that may be used to increase our understanding of the aerosol and ion dynamics in the atmosphere that can be important to various aerosol process parameterization and to global model validation.

This work is part of a protocol work done within an ACTRIS community. The ACTRIS is an European Research Infrastructure for the observation of Aerosol, Clouds, and Trace gases, and it aims to serve a vast community working on models and forecast systems by offering high quality atmospheric data. Several large-scale modelling studies have demonstrated that more reliable nucleation parameterizations than currently available are needed to evaluate the importance of nucleation in climate (Spracklen et al., 2006; Makkonen et al., 2009; Merikanto et al., 2009; Pierce and Adams, 2009; Yu, 2010). Based on the NAIS results, nucleation parameterizations (e.g. size-dependent atmospheric nanoparticle growth and nucleation favouring ion processes) already exist for large-scale modelling but no global model is using those (see Nieminen et al., 2011; Kontkanen et al., 2013; Häkkinen et al., 2013). Overall, the large goal is to integrate the NAIS to various international research networks as a standard instrument to detect the atmospheric nanoparticles when studying climate and air quality, and to increase the utilization of existing extensive NAIS datasets. By improving the accuracy and comparability of the measurements and instrument laboratory characterization, we also improve the fundamental understanding on the atmospheric ion and aerosol population and the physical processes affecting the population dynamics.

\section{Code availability}

All codes necessary for a reader to understand and evaluate the conclusions of the paper will be archived in an approved database and made available to any user via personal communication to authors.

\section{Data availability}

All data necessary for a reader to understand and evaluate the conclusions of the paper are included in the paper or its supplement or will be archived in an approved database and made available to any user via personal communication to authors. The ion number size distribution data presented in the figures is accessible at the EMEP database (http://ebas. nilu.no). 


\section{The Supplement related to this article is available online at doi:10.5194/amt-9-3577-2016-supplement.}

Author contributions. H. E. Manninen was primarily responsible for the design and interpretation of the reported experiments. S. Mirme and A. Mirme provided technical support, and T. Petäjä and M. Kulmala administrative and supervisory support that made a direct substantial intellectual contribution to this research. H. E. Manninen prepared the manuscript with contributions from all co-authors.

Acknowledgements. This work is based on the long-term experience by the University of Helsinki (UHEL) performing field, laboratory and chamber measurements with the NAIS, and the SOPs written by the UHEL working group for the ACTRIS community (the European Union's FP7 capacities programme under grant no. 262254, and Horizon 2020 research and innovation programme under grant no. 654109). We acknowledge John Backman, Alessando Franchin, Janne Lampilahti, Katri Leino, and Ville Vakkari for their contribution on providing material for this SOP. UHEL acknowledges the Academy of Finland Centre of Excellence (grant no. 272041). H. E. Manninen acknowledges support by the Finnish Cultural Foundation (grant no. 00121082). S. Mirme and A. Mirme acknowledge the Estonian Research Council Project (grant no. IUT20-11), the European Regional Development Fund through the Environmental Conservation and Environmental Technology R\&D Programme project BioAtmos (grant no. 3.2.0802.11-0043), and the "Estonian Research Infrastructures Roadmap" project Estonian Environmental Observatory (grant no. 3.2.0304.11-0395).

Edited by: J. Curtius

Reviewed by: two anonymous referees

\section{References}

Allen, M. D. and Raabe, O. G.: Slip Correction Measurements of Spherical Solid Aerosol Particles in an Improved Millikan Apparatus, Aerosol Sci. Tech., 4, 269-286, doi:10.1080/02786828508959055, 1985.

Asmi, E., Sipilä, M., Manninen, H. E., Vanhanen, J., Lehtipalo, K., Gagné, S., Neitola, K., Mirme, A., Mirme, S., Tamm, E., Uin, J., Komsaare, K., Attoui, M., and Kulmala, M.: Results of the first air ion spectrometer calibration and intercomparison workshop, Atmos. Chem. Phys., 9, 141-154, doi:10.5194/acp-9-141-2009, 2009.

Alguacil, F. J. and Alonso, M.: Multiple charging of ultrafine particles in a corona charger, J. Aerosol Sci., 37, 875-884, 2006.

Alonso, M., Martin, M. I., and Alguacil, F. J.: The measurement of charging efficiencies and losses of aerosol nanoparticles in a corona charger, J. Electrostat., 64, 203-214, doi:10.1016/j.elstat.2005.05.008, 2006.
Backman, J., Rizzo, L. V., Hakala, J., Nieminen, T., Manninen, H. E., Morais, F., Aalto, P. P., Siivola, E., Carbone, S., Hillamo, R., Artaxo, P., Virkkula, A., Petäjä, T., and Kulmala, M.: On the diurnal cycle of urban aerosols, black carbon and the occurrence of new particle formation events in springtime São Paulo, Brazil, Atmos. Chem. Phys., 12, 11733-11751, doi:10.5194/acp12-11733-2012, 2012.

Boulon, J., Sellegri, K., Hervo, M., Picard, D., Pichon, J.-M., Fréville, P., and Laj, P.: Investigation of nucleation events vertical extent: a long term study at two different altitude sites, Atmos. Chem. Phys., 11, 5625-5639, doi:10.5194/acp-11-56252011, 2011.

Dos Santos, V. N., Herrmann, E., Manninen, H. E., Hussein, T., Hakala, J., Nieminen, T., Aalto, P. P., Merkel, M., Wiedensohler, A., Kulmala, M., Petäjä, T., and Hämeri, K.: Variability of air ion concentrations in urban Paris, Atmos. Chem. Phys., 15, 1371713737, doi:10.5194/acp-15-13717-2015, 2015.

Duplissy, J., Merikanto, J., Franchin, A., Tsagkogeorgas, G., Kangasluoma, J.,Wimmer, D., Vuollekoski, H., Schobesberger, S., Lehtipalo, K., Flagan, R. C., Brus, D., Donahue, N. M., Vehkamäki, H., Almeida, J., Amorim, A., Barmet, P., Bianchi, F., Breitenlechner, M., Dunne, E. M., Guida, R., Henschel, H., Junninen, H., Kirkby, J., Kürten, A., Kupc, A., Määttänen, A., Makhmutov, V., Mathot, S., Nieminen, T., Onnela, A., Praplan, A. P., Riccobono, F., Rondo, L., Steiner, G., Tome, A., Walther, H., Baltensperger, U., Carslaw, K. S., Dommen, J., Hansel, A., Petäjä, T., Sipilä, M., Stratmann, F., Vrtala, A., Wagner, P. E., Worsnop, D. R., Curtius, J., and Kulmala, M.: Effect of ions on sulfuric acid-water binary particle formation: 2 . Experimental data and comparison with QC-normalized classical nucleation theory, J. Geophys. Res.-Atmos., 121, 1752-1775, doi:10.1002/2015JD023539, 2016.

Ehn, M., Junninen, H., Schobesberger, S., Manninen, H. E., Franchin, A., and Sipilä, M.: An Instrumental Comparison of Mobility and Mass Measurements of Atmospheric Small Ions, Aerosol Sci. Technol., 43, 522-532, 2011.

Ehn, M., Thornton, J. A., Kleist, E., Sipilä, M., Junninen, H., Pullinen, I., Springer, M., Rubach, F., Tillmann, R., Lee, B., LopezHilfiker, F., Andres, S., Acir, I.-H., Rissanen, M., Jokinen, T., Schobesberger, S., Kangasluoma, J., Kontkanen, J., Nieminen, T., Kurtén, T., Nielsen, L. B., Jørgensen, S., Kjaergaard, H. G., Canagaratna, M., Maso, M. D., Berndt, T., Petäjä, T., Wahner, A., Kerminen, V.-M., Kulmala, M., Worsnop, D. R., Wildt, J. and Mentel, T. F.: A large source of low-volatility secondary organic aerosol, Nature, 506, 476-479, 2014.

Franchin, A., Ehrhart, S., Leppä, J., Nieminen, T., Gagné, S., Schobesberger, S., Wimmer, D., Duplissy, J., Riccobono, F., Dunne, E. M., Rondo, L., Downard, A., Bianchi, F., Kupc, A., Tsagkogeorgas, G., Lehtipalo, K., Manninen, H. E., Almeida, J., Amorim, A., Wagner, P. E., Hansel, A., Kirkby, J., Kürten, A., Donahue, N. M., Makhmutov, V., Mathot, S., Metzger, A., Petäjä, T., Schnitzhofer, R., Sipilä, M., Stozhkov, Y., Tomé, A., Kerminen, V.-M., Carslaw, K., Curtius, J., Baltensperger, U., and Kulmala, M.: Experimental investigation of ion-ion recombination under atmospheric conditions, Atmos. Chem. Phys., 15, 72037216, doi:10.5194/acp-15-7203-2015, 2015.

Fuchs, N. A. and Sutugin, A. G.: Highly dispersed aerosol, in: Topics in current aerosol research (Part 2), edited by: Hidy, G. M. and Brock, J. R., Pergamon, New York, 1-60, 1971. 
Gagné, S., Lehtipalo, K., Manninen, H. E., Nieminen, T., Schobesberger, S., Franchin, A., Yli-Juuti, T., Boulon, J., Sonntag, A., Mirme, S., Mirme, A., Hõrrak, U., Petäjä, T., Asmi, E., and Kulmala, M.: Intercomparison of air ion spectrometers: an evaluation of results in varying conditions, Atmos. Meas. Tech., 4, 805-822, doi:10.5194/amt-4-805-2011, 2011.

Häkkinen, S. A. K., Manninen, H. E., Yli-Juuti, T., Merikanto, J., Kajos, M. K., Nieminen, T., D’Andrea, S. D., Asmi, A., Pierce, J. R., Kulmala, M., and Riipinen, I.: Semi-empirical parameterization of size-dependent atmospheric nanoparticle growth in continental environments, Atmos. Chem. Phys., 13, 7665-7682, doi:10.5194/acp-13-7665-2013, 2013.

Harrison, R. G. and Carslaw, K. S.: Ion-aerosol-cloud processes in the lower atmosphere, Rev. Geophys., 41, 1012, doi:10.1029/2002RG000114, 2003.

Herrmann, W., Eichler, T., Bernardo, N., and Fernández de la Mora, J.: Turbulent transition arises at Re 35000 in a short Viennatype DMA with a large laminarizing inlet, Abstract to the annual conference of the AAAR, 2000.

Herrmann, E., Ding, A. J., Kerminen, V.-M., Petäjä, T., Yang, X. Q., Sun, J. N., Qi, X. M., Manninen, H., Hakala, J., Nieminen, T., Aalto, P. P., Kulmala, M., and Fu, C. B.: Aerosols and nucleation in eastern China: first insights from the new SORPES-NJU station, Atmos. Chem. Phys., 14, 2169-2183, doi:10.5194/acp14-2169-2014, 2014.

Hinds, W. C.: Aerosol Technology, Properties, Behavior, and Measurement of Airborne Particles, Wiley, New York, 1982.

Hirsikko, A., Yli-Juuti, T., Nieminen, T., Vartiainen, E., Laakso, L., Hussein, T. and Kulmala, M.: Indoor and outdoor air ions and aerosol particles in the urban atmosphere of Helsinki: characteristics, sources and formation, Boreal Env. Res., 12, 295-310, 2007.

Hirsikko, A., Nieminen, T., Gagné, S., Lehtipalo, K., Manninen, H. E., Ehn, M., Hõrrak, U., Kerminen, V.-M., Laakso, L., McMurry, P. H., Mirme, A., Mirme, S., Petäjä, T., Tammet, H., Vakkari, V., Vana, M., and Kulmala, M.: Atmospheric ions and nucleation: a review of observations, Atmos. Chem. Phys., 11, 767798, doi:10.5194/acp-11-767-2011, 2011.

Hirsikko, A., Vakkari, V., Tiitta, P., Hatakka, J., Kerminen, V.-M., Sundström, A.-M., Beukes, J. P., Manninen, H. E., Kulmala, M., and Laakso, L.: Multiple daytime nucleation events in semi-clean savannah and industrial environments in South Africa: analysis based on observations, Atmos. Chem. Phys., 13, 5523-5532, doi:10.5194/acp-13-5523-2013, 2013.

Hoppel, W. A.: Theory of the electrode effect, J. Atmos. Terr. Phys., 29, 709-721, 1967.

Hõrrak, U.: Air ion mobility spectrum at a rural area, in: Dissertationes Geophysicales Universitatis Tartuensis, 15, Tartu Univ. Press, Tartu, available at: http://ael.physic.ut.ee/KF.Private/ Urmas.Horrak/PhDVeeb/PhD-UH.htm, 2001.

Huang, C.-H. and Alonso, M.: Nanoparticle electrostatic loss within corona needle charger during particle-charging process, J. Nanopart. Res., 13, 175-184, 2011.

Intra, P. and Tippayawong, N.: Progress in unipolar corona discharger designs for airborne particle charging: A literature review, J. Electrostatics., 67, 605-615, 2009.

IPCC: Climate Change 2013: The Physical Science Basis, Contribution of Working Group I to the Fifth Assessment Report of the Intergovernmental Panel on Climate Change, Cambridge
University Press, Cambridge, UK and New York, NY, USA, available at: http://www.climatechange2013.org/images/report/ WG1AR5_ALL_FINAL.pdf, 1535 pp., 2013.

Israël, H.: Atmospheric Electricity, Vol. I: Israel Program for Scientific Translations, Jerusalem, 317 pp., 1970.

Jayaratne, E. R., Ling, X., and Morawska, L.: Observation of ions and particles near busy roads using a neutral cluster and air ion spectrometer (NAIS), Atmos. Environ., 84, 198-203, 2014.

Jayaratne, R. E., Ling, X., and Morawska, L.: Suppression of cluster ions during rapidly increasing particle number concentration events in the environment, Aerosol Air Qual. Res., 15, 28-37, 2015.

Kangasluoma, J., Junninen, H., Lehtipalo, K., Mikkilä, J., Vanhanen, J., Attoui, M., Sipilä, M., Worsnop, D. R., Kulmala, M., and Petäjä, T.: Remarks on ion generation for CPC detection efficiency studies in sub-3-m size range, Aerosol Sci. Technol., 47, 556-563, 2013.

Kangasluoma, J., Attoui, M., Korhonen, F., Ahonen, L., Siivola, E., and Petäjä, T.: Characterization of a Herrmann-type highresolution differential mobility analyzer, Aerosol Sci. Technol., 50, 222-229, 2016.

Kerminen, V.-M., Petäjä, T., Manninen, H. E., Paasonen, P., Nieminen, T., Sipilä, M., Junninen, H., Ehn, M., Gagné, S., Laakso, L., Riipinen, I., Vehkamäki, H., Kurten, T., Ortega, I. K., Dal Maso, M., Brus, D., Hyvärinen, A., Lihavainen, H., Leppä, J., Lehtinen, K. E. J., Mirme, A., Mirme, S., Hõrrak, U., Berndt, T., Stratmann, F., Birmili, W., Wiedensohler, A., Metzger, A., Dommen, J., Baltensperger, U., Kiendler-Scharr, A., Mentel, T. F., Wildt, J., Winkler, P. M., Wagner, P. E., Petzold, A., Minikin, A., Plass-Dülmer, C., Pöschl, U., Laaksonen, A., and Kulmala, M.: Atmospheric nucleation: highlights of the EUCAARI project and future directions, Atmos. Chem. Phys., 10, 10829-10848, doi:10.5194/acp-10-10829-2010, 2010.

Kim, J. H., Mulholland, G. W., Kukuck, S. R., and Pui, D. Y. H.: Slip correction measurements of certified PSL nanoparticles using a nanometer Differential Mobility Particle Analyzer (Nano-DMA) for Knudsen number from 0.5 to 83 , J. Res. Natl. Inst. Stand. Technol., 110, 31-54, 2005.

Kirkby, J., Duplissy, J., Sengupta, K., Frege, C., Gordon, H., Williamson, C., Heinritzi, M., Simon, M., Yan, C., Almeida, J., Tröstl, J., Nieminen, T., Ortega, I. K., Wagner, R., Adamov, A., Amorim, A., Bernhammer, A.-K., Bianchi, F., Breitenlechner, M., Brilke, S., Chen, X., Craven, J., Dias, A., Ehrhart, S., Flagan, R. C., Franchin, A., Fuchs, C., Guida, R., Hakala, J., Hoyle, C. R., Jokinen, T., Junninen, H., Kangasluoma, J., Kim, J., Krapf, M., Kürten, A., Laaksonen, A., Lehtipalo, K., Makhmutov, V., Mathot, S., Molteni, U., Onnela, A., Peräkylä, O., Piel, F., Petäjä, T., Praplan, A. P., Pringle, K., Rap, A., Richards, N. A. D., Riipinen, I., Rissanen, M. P., Rondo, L., Sarnela, N., Schobesberger, S., Scott, C. E., Seinfeld, J. H., Sipilä, M., Steiner, G., Stozhkov, Y., Stratmann, F., Tomé, A., Virtanen, A., Vogel, A. L., Wagner, A. C., Wagner, P. E., Weingartner, E., Wimmer, D., Winkler, P. M., Ye, P., Zhang, X., Hansel, A., Dommen, J., Donahue, N. M., Worsnop, D. R., Baltensperger, U., Kulmala, M., Carslaw, K. S., Curtius, J.: Ion-induced nucleation of pure biogenic particles, Nature, 533, 521-526, doi:10.1038/nature17953, 2016.

Kontkanen, J., Lehtinen, K. E. J., Nieminen, T., Manninen, H. E., Lehtipalo, K., Kerminen, V.-M., and Kulmala, M.: Estimating the contribution of ion-ion recombination to sub- $2 \mathrm{~nm}$ cluster 
concentrations from atmospheric measurements, Atmos. Chem. Phys., 13, 11391-11401, doi:10.5194/acp-13-11391-2013, 2013. Kulmala, M., Riipinen, I., Sipilä, M., Manninen, H. E., Petäjä, T., Junninen, H., Dal Maso, M., Mordas, G., Mirme, A., Vana, M., Hirsikko, A., Laakso, L., Harrison, R. M., Hanson, I., Leung, C., Lehtinen, K. E. J. and Kerminen, V.-M.: Towards direct measurements of atmospheric nucleation, Science, 318, 89-92, 2007.

Kulmala, M., Asmi, A., Lappalainen, H. K., Baltensperger, U., Brenguier, J.-L., Facchini, M. C., Hansson, H.-C., Hov, Ø., O'Dowd, C. D., Pöschl, U., Wiedensohler, A., Boers, R., Boucher, O., de Leeuw, G., Denier van der Gon, H. A. C., Feichter, J., Krejci, R., Laj, P., Lihavainen, H., Lohmann, U., McFiggans, G., Mentel, T., Pilinis, C., Riipinen, I., Schulz, M., Stohl, A., Swietlicki, E., Vignati, E., Alves, C., Amann, M., Ammann, M., Arabas, S., Artaxo, P., Baars, H., Beddows, D. C. S., Bergström, R., Beukes, J. P., Bilde, M., Burkhart, J. F., Canonaco, F., Clegg, S. L., Coe, H., Crumeyrolle, S., D’Anna, B., Decesari, S., Gilardoni, S., Fischer, M., Fjaeraa, A. M., Fountoukis, C., George, C., Gomes, L., Halloran, P., Hamburger, T., Harrison, R. M., Herrmann, H., Hoffmann, T., Hoose, C., Hu, M., Hyvärinen, A., Hõrrak, U., Iinuma, Y., Iversen, T., Josipovic, M., Kanakidou, M., Kiendler-Scharr, A., Kirkevåg, A., Kiss, G., Klimont, Z., Kolmonen, P., Komppula, M., Kristjánsson, J.-E., Laakso, L., Laaksonen, A., Labonnote, L., Lanz, V. A., Lehtinen, K. E. J., Rizzo, L. V., Makkonen, R., Manninen, H. E., McMeeking, G., Merikanto, J., Minikin, A., Mirme, S., Morgan, W. T., Nemitz, E., O’Donnell, D., Panwar, T. S., Pawlowska, H., Petzold, A., Pienaar, J. J., Pio, C., Plass-Duelmer, C., Prévôt, A. S. H., Pryor, S., Reddington, C. L., Roberts, G., Rosenfeld, D., Schwarz, J., Seland, Ø., Sellegri, K., Shen, X. J., Shiraiwa, M., Siebert, H., Sierau, B., Simpson, D., Sun, J. Y., Topping, D., Tunved, P., Vaattovaara, P., Vakkari, V., Veefkind, J. P., Visschedijk, A., Vuollekoski, H., Vuolo, R., Wehner, B., Wildt, J., Woodward, S., Worsnop, D. R., van Zadelhoff, G.-J., Zardini, A. A., Zhang, K., van Zyl, P. G., Kerminen, V.-M., S Carslaw, K., and Pandis, S. N.: General overview: European Integrated project on Aerosol Cloud Climate and Air Quality interactions (EUCAARI) - integrating aerosol research from nano to global scales, Atmos. Chem. Phys., 11, 13061-13143, doi:10.5194/acp11-13061-2011, 2011.

Kulmala, M., Petäjä, T., Nieminen, T., Sipilä, M., Manninen, H. E., Lehtipalo, K., DalMaso, M., Aalto, P. P., Junninen, H., Paasonen, P., Riipinen, I., Lehtinen, K. E. J., Laaksonen, A., and Kulmala, M.: Measurement of the nucleation of atmospheric aerosol particles, Nature Protocols, 7, 1651-1667, 2012.

Kulmala, M., Kontkanen, J., Junninen, H., Lehtipalo, K., Manninen, H. E., Nieminen, T., Petäjä, T., Sipilä, M., Schobesberger, S., Rantala, P., Franchin, A., Jokinen, T., Järvinen, E., Äijälä, M., Kangasluoma, J., Hakala, J., Aalto, P. P., Paasonen, P., Mikkilä, J., Vanhanen, J., Aalto, J., Hakola, H., Makkonen, U., Ruuskanen, T., Mauldin, R. L., Duplissy, J., Vehkamäki, H., Bäck, J., Kortelainen, A., Riipinen, I., Kurten, T., Johnston, M. V., Smith, J. N., Ehn, M., Mentel, T. F., Lehtinen, K. E. J., Laaksonen, A., Kerminen, V.-M., and Worsnop, D. R.: Direct observation of atmospheric aerosol nucleation, Science, 339, 943-946, 2013.

Kulmala, M., Petäjä, T., Ehn, M., Thornton, J., Sipilä, M., Worsnop, D. R., and Kerminen, V.-M.: Chemistry of atmospheric nucleation: on the recent advances on precursor characterization and atmospheric cluster composition in connection with atmospheric particle formation, Annu. Rev. Phys. Chem., 65, 21-37, 2014.

Laakso, L., Grönholm, T., Kulmala, L., Haapanala, S., Hirsikko, A., Lovejoy, E. R., Kazil, J., Kurtén, T., Boy, M., Nilsson, E. D., Sogachev, A., Riipinen, I., Stratmann, F., and Kulmala, M.: Hotair balloon as a platform for boundary layer profile measurements during particle formation, Boreal Env. Res., 12, 279-294, 2007.

Lehtipalo, K., Sipilä, M., Riipinen, I., Nieminen, T., and Kulmala, M.: Analysis of atmospheric neutral and charged molecular clusters in boreal forest using pulse-height CPC, Atmos. Chem. Phys., 9, 4177-4184, doi:10.5194/acp-9-4177-2009, 2009.

Lehtipalo, K., Kulmala, M., Sipilä, M., Petäjä, T., Vana, M., Ceburnis, D., Dupuy, R., and O'Dowd, C.: Nanoparticles in boreal forest and coastal environment: a comparison of observations and implications of the nucleation mechanism, Atmos. Chem. Phys., 10, 7009-7016, doi:10.5194/acp-10-7009-2010, 2010.

Leino, K., Nieminen, T., Manninen, H.E., Petäjä, T., Kerminen, V.M., and Kulmala, M.: Intermediate ions as a strong indicator for new particle formation bursts in a boreal forest, Boreal Env. Res., 21, 274-286, 2016.

Leppä, J., Kerminen, V.-M., Laakso, L., Korhonen, H., Lehtinen, K. E. J., Gagné, S., Manninen, H. E., Nieminen, T., and Kulmala, M.: Ion-UHMA: a model for simulating the dynamics of neutral and charged aerosol particles, Boreal Env. Res., 14, 559-575, 2009.

Lihavainen, H., Komppula, M., Kerminen, V.-M., Järvinen, H., Viisanen, Y., Lehtinen, K., Vana, M., and Kulmala, M.: Size distributions of atmospheric ions inside clouds and in cloud-free air at a remote continental site, Boreal Env. Res., 12, 337-344, 2007.

Lovejoy, E. R., Curtius, J., and Froyd, K. D.: Atmospheric ioninduced nucleation of sulfuric acid and water, J. Geophys. Res., 109, D08204, doi:10.1029/2003JD004460, 2004.

Makkonen, R., Asmi, A., Korhonen, H., Kokkola, H., Järvenoja, S., Räisänen, P., Lehtinen, K. E. J., Laaksonen, A., Kerminen, V.M., Järvinen, H., Lohmann, U., Bennartz, R., Feichter, J., and Kulmala, M.: Sensitivity of aerosol concentrations and cloud properties to nucleation and secondary organic distribution in ECHAM5-HAM global circulation model, Atmos. Chem. Phys., 9, 1747-1766, doi:10.5194/acp-9-1747-2009, 2009.

Manninen, H. E.: Direct detection of atmospheric particle formation using the Neutral cluster and Air Ion Spectrometer, $\mathrm{PhD}$ thesis, Aerosolitutkimusseura, Helsinki, 2011.

Manninen, H. E., Petäjä, T., Asmi, E., Riipinen, I., Nieminen, T., Mikkilä, J., Hõrrak, U., Mirme, A., Mirme, S., Laakso, L., Kerminen, V.-M., and Kulmala, M.: Long-term field measurements of charged and neutral clusters using Neutral cluster and Air Ion Spectrometer (NAIS), Boreal Env. Res., 14, 591-605, 2009.

Manninen, H. E., Nieminen, T., Asmi, E., Gagné, S., Häkkinen, S., Lehtipalo, K., Aalto, P., Vana, M., Mirme, A., Mirme, S., Hõrrak, U., Plass-Dülmer, C., Stange, G., Kiss, G., Hoffer, A., Töro, N., Moerman, M., Henzing, B., de Leeuw, G., Brinkenberg, M., Kouvarakis, G. N., Bougiatioti, A., Mihalopoulos, N., O'Dowd, C., Ceburnis, D., Arneth, A., Svenningsson, B., Swietlicki, E., Tarozzi, L., Decesari, S., Facchini, M. C., Birmili, W., Sonntag, A., Wiedensohler, A., Boulon, J., Sellegri, K., Laj, P., Gysel, M., Bukowiecki, N., Weingartner, E., Wehrle, G., Laaksonen, A., Hamed, A., Joutsensaari, J., Petäjä, T., Kerminen, V.-M., and Kulmala, M.: EUCAARI ion spectrometer measurements at 12 European sites - analysis of new particle formation events, 
Atmos. Chem. Phys., 10, 7907-7927, doi:10.5194/acp-10-79072010, 2010.

Manninen, H. E., Franchin, A., Schobesberger, S., Hirsikko, A., Hakala, J., Skromulis, A., Kangasluoma, J., Ehn, M., Junninen, H., Mirme, A., Mirme, S., Sipilä, M., Petäjä, T., Worsnop, D. R., and Kulmala, M.: Characterisation of corona-generated ions used in a Neutral cluster and Air Ion Spectrometer (NAIS), Atmos. Meas. Tech., 4, 2767-2776, doi:10.5194/amt-4-2767-2011, 2011.

McMurry, P. H., Ghimire, A., Ahn, H.-K., Sakurai, H., Moore, K., Stolzenburg, M. R., and Smith, J.: Sampling Nanoparticles for Chemical Analysis by Low Resolution Electrical Mobility Classification, Environ. Sci. Technol., 43, 4653-4658, 2009.

Merikanto, J., Spracklen, D. V., Mann, G. W., Pickering, S. J., and Carslaw, K. S.: Impact of nucleation on global CCN, Atmos. Chem. Phys., 9, 8601-8616, doi:10.5194/acp-9-8601-2009, 2009.

Mirme, A., Tamm, E., Mordas, G., Vana, M., Uin, J., Mirme, S., Bernotas, T., Laakso, L., Hirsikko, A., and Kulmala, M.: Widerange multi-channel Air Ion Spectrometer, Boreal Env. Res., 12, 247-264, 2007.

Mirme, S. and Mirme, A.: The mathematical principles and design of the NAIS - a spectrometer for the measurement of cluster ion and nanometer aerosol size distributions, Atmos. Meas. Tech., 6, 1061-1071, doi:10.5194/amt-6-1061-2013, 2013.

Mirme, S., Mirme, A., Minikin, A., Petzold, A., Hõrrak, U., Kerminen, V.-M., and Kulmala, M.: Atmospheric sub-3 nm particles at high altitudes, Atmos. Chem. Phys., 10, 437-451, doi:10.5194/acp-10-437-2010, 2010.

Mäkelä, J. M., Riihelä, M., Ukkonen, A., Jokinen, V., and Keskinen, J.: Comparison of mobility equivalent diameter with KelvinThomson diameter using ion mobility data, J. Chem. Phys., 105, 1562-1571, 1996.

Martin, S. T., Andreae, M. O., Artaxo, P., Baumgardner, D., Chen, Q., Goldstein, A. H., Guenther, A., Heald, C. L., Mayol-Bracero, O. L., McMurry, P. H., Pauliquevis, T., Pöschl, U., Prather, K. A., Roberts, G. C., Saleska, S. R., Silva-Dias, M. A., Spracklen, D. V., Swietlicki, E., and Trebs, I.: Sources and properties of Amazonian aerosol particles, Rev. Geophys., 48, RG2002, doi:10.1029/2008RG000280, 2010.

Nieminen, T., Paasonen, P., Manninen, H. E., Sellegri, K., Kerminen, V.-M., and Kulmala, M.: Parameterization of ion-induced nucleation rates based on ambient observations, Atmos. Chem. Phys., 11, 3393-3402, doi:10.5194/acp-11-3393-2011, 2011.

Ortega, I. K., Suni, T., Boy, M., Grönholm, T., Manninen, H. E., Nieminen, T., Ehn, M., Junninen, H., Hakola, H., Hellén, H., Valmari, T., Arvela, H., Zegelin, S., Hughes, D., Kitchen, M., Cleugh, H., Worsnop, D. R., Kulmala, M., and Kerminen, V.-M.: New insights into nocturnal nucleation, Atmos. Chem. Phys., 12, 4297-4312, doi:10.5194/acp-12-4297-2012, 2012.

Pierce, J. R. and Adams, P. J.: Uncertainty in global CCN concentrations from uncertain aerosol nucleation and primary emission rates, Atmos. Chem. Phys., 9, 1339-1356, doi:10.5194/acp-91339-2009, 2009.

Reischl, G. P., Mäkelä, J. M., and Necid, J.: Performance of Vienna type differential mobility analyzer at 1.2-20 nanometer, Aerosol Sci. Technol., 27, 651-672, 1997.

Rose, C., Sellegri, K., Velarde, F., Moreno, I., Ramonet, M., Weinhold, K., Krejci, R., Andrade, M., Wiedensohler, A., and Laj, P.:
Frequent nucleation events at the high altitude station of Chacaltaya (5240 m a.s.1.), Bolivia, Atmos. Environ., 102, 18-29, 2015.

Siingh, D., Gautam, A. S., Kamra, A. K., and Komsaare, K.: Nucleation events for the formation of charged aerosol particles at a tropical station - Preliminary results, Atmos. Res., 132, 239252, 2013.

Spracklen, D. V., Carslaw, K. S., Kulmala, M., Kerminen, V.-M., Mann, G. W., and Sihto, S.-L.: The contribution of boundary layer nucleation events to total particle concentrations on regional and global scales, Atmos. Chem. Phys., 6, 5631-5648, doi:10.5194/acp-6-5631-2006, 2006.

Steiner, G., Jokinen, T., Junninen, H., Sipilä, M., Petäjä, T., Worsnop, D., Reischl, G. P., and Kulmala, M.: High-Resolution Mobility and Mass Spectrometry of Negative Ions Produced in a 241 Am Aerosol Charger, Aerosol Sci. Technol., 48, 261-270, 2014.

Suni, T., Kulmala, M., Hirsikko, A., Bergman, T., Laakso, L., Aalto, P. P., Leuning, R., Cleugh, H., Zegelin, S., Hughes, D., van Gorsel, E., Kitchen, M., Vana, M., Hõrrak, U., Mirme, S., Mirme, A., Sevanto, S., Twining, J., and Tadros, C.: Formation and characteristics of ions and charged aerosol particles in a native Australian Eucalypt forest, Atmos. Chem. Phys., 8, 129-139, doi:10.5194/acp-8-129-2008, 2008

Tammet, H.: Size and mobility of nanometer particles, clusters and ions, J. Aerosol Sci., 26, 459-475, 1995.

Tammet, H., Hõrrak, U., and Kulmala, M.: Negatively charged nanoparticles produced by splashing of water, Atmos. Chem. Phys., 9, 357-367, doi:10.5194/acp-9-357-2009, 2009.

Tiitta, P., Miettinen, P., Vaattovaara, P., Laaksonen, A., Joutsensaari, J., Hirsikko, A., Aalto, P., and Kulmala, M.: Road-side measurements of aerosol and ion number size distributions: a comparison with remote site measurements, Boreal Env. Res., 12, 311-321, 2007.

Ude, S. and Fernández de la Mora, J.: Molecular monodisperse mobility and mass standards from electrosprays of tetra-alkyl ammonium halides, J. Aerosol Sci., 36, 1224-1237, 2005.

Vartiainen, E., Kulmala, M., Ruuskanen, T. M., Taopale, R., Rinne, J., and Vehkamäki, H.: Formation and growth of indoor air aerosol particles as a result of d-limonene oxidation, Atmos. Environ., 40, 7882-7892, 2006.

Virkkula, A., Hirsikko, A., Vana, M., Aalto, P. P., Hillamo, R., and Kulmala, M.: Charged particle size distributions and analysis of particle formation events at the Finnish Antarctic research station Aboa, Boreal Env. Res., 12, 397-408, 2007.

Wang, J., Flagan, R., and Seinfeld, J.: Diffusional losses in particle sampling systems containing bends and elbows, Aerosol Sci. Technol., 33, 843-857, 2002.

Wagner, R., Manninen, H. E., Franchin, A., Lehtipalo, K., Mirme, S., Steiner, G., Petäjä, T., and Kulmala, M.: On the accuracy of ion measurements using a Neutral cluster and Air Ion Spectrometer, Boreal Env. Res., 21, 230-241, 2016.

Winklmayr, W., Reischl, G. P., Lindner, A. O., and A. Berner, A.: A new electromobility spectrometer for the measurement of aerosol size distribution in the range from 1 to $100 \mathrm{~nm}$, J. Aerosol Sci., 22, 289-296, 1991.

Wiedensohler, A.: An approximation of the bipolar charge distribution for particles in the submicron size range, J. Aerosol Sci., 19, 387-389, 1988. 
Wiedensohler, A., Birmili, W., Nowak, A., Sonntag, A., Weinhold, K., Merkel, M., Wehner, B., Tuch, T., Pfeifer, S., Fiebig, M., Fjäraa, A. M., Asmi, E., Sellegri, K., Depuy, R., Venzac, H., Villani, P., Laj, P., Aalto, P., Ogren, J. A., Swietlicki, E., Williams, P., Roldin, P., Quincey, P., Hüglin, C., Fierz-Schmidhauser, R., Gysel, M., Weingartner, E., Riccobono, F., Santos, S., Grüning, C., Faloon, K., Beddows, D., Harrison, R., Monahan, C., Jennings, S. G., O’Dowd, C. D., Marinoni, A., Horn, H.-G., Keck, L., Jiang, J., Scheckman, J., McMurry, P. H., Deng, Z., Zhao, C. S., Moerman, M., Henzing, B., de Leeuw, G., Löschau, G., and Bastian, S.: Mobility particle size spectrometers: harmonization of technical standards and data structure to facilitate high quality long-term observations of atmospheric particle number size distributions, Atmos. Meas. Tech., 5, 657-685, doi:10.5194/amt5-657-2012, 2012.
Yli-Juuti, T., Nieminen, T., Hirsikko, A., Aalto, P. P., Asmi, E., Hõrrak, U., Manninen, H. E., Patokoski, J., Dal Maso, M., Petäjä, T., Rinne, J., Kulmala, M., and Riipinen, I.: Growth rates of nucleation mode particles in Hyytiälä during 20032009: variation with particle size, season, data analysis method and ambient conditions, Atmos. Chem. Phys., 11, 12865-12886, doi:10.5194/acp-11-12865-2011, 2011.

Yu, F.: Ion-mediated nucleation in the atmosphere: Key controlling parameters, implications, and look-up table, J. Geophys. Res., 115, D03206, doi:10.1029/2009JD012630, 2010.

Zhang, R., Khalizov, A., Wang, L., Hu, M., and Xu, W.: Nucleation and growth of nanoparticles in the atmosphere, Chem. Rev., 112, 1957-2011, 2012. 